\title{
Bayesian estimation of the hydraulic and solute transport properties of a small-scale unsaturated soil column
}

\author{
Paulo H. S. Moreira, Martinus Th. van Genuchten, Helcio R. B. Orlande*, Renato M. Cotta \\ DEM/PEM - Politécnica/COPPE, Federal University of Rio de Janeiro, UFRJ, Caixa Postal 68503, Cidade Universitária, Rio de Janeiro, \\ 21941-972, Brazil. \\ * Corresponding author. E-mail: helcio@mecanica.coppe.ufrj.br
}

\begin{abstract}
In this study the hydraulic and solute transport properties of an unsaturated soil were estimated simultaneously from a relatively simple small-scale laboratory column infiltration/outflow experiment. As governing equations we used the Richards equation for variably saturated flow and a physical non-equilibrium dual-porosity type formulation for solute transport. A Bayesian parameter estimation approach was used in which the unknown parameters were estimated with the Markov Chain Monte Carlo (MCMC) method through implementation of the Metropolis-Hastings algorithm. Sensitivity coefficients were examined in order to determine the most meaningful measurements for identifying the unknown hydraulic and transport parameters. Results obtained using the measured pressure head and solute concentration data collected during the unsaturated soil column experiment revealed the robustness of the proposed approach.
\end{abstract}

Keywords: Markov Chain Monte Carlo method; Metropolis-Hastings algorithm; Hydraulic parameters; Transport parameters; Soil column experiment.

\section{INTRODUCTION}

Efficient methods for accurately estimating physical and geochemical parameters of mathematical models for the analysis of soil, hydrologic and contaminant transport problems are critically needed. A large number of increasingly sophisticated public domain and commercial software packages are now available for a broad range of applications, including coupled vadose zone-groundwater systems (Miller et al., 2013; Šimůnek and Bradford, 2008). While a range of experimental techniques are now available for measuring the physical properties of soils (Dane and Topp, 2002), many of the standard procedures are based on assumptions that simplify the mathematical analysis, such as one-dimensional flow, steady-state flow conditions and/or homogeneous media properties. At the same time, more complicated and often nonlinearly coupled physical and biogeochemical processes are being included in the models for relevant applications. Therefore, proper formulations and solutions of the associated parameter estimation problems (Beck and Arnold, 1977) are needed to provide estimates for the required subsurface media and contaminant transport properties.

Many methods and techniques are available for estimating flow and transport soil properties. In this study a Bayesian estimator is used to identify the conditional probability distribution of the unknown properties given the measurements (i.e., the posterior probability density). The measurement model that incorporates the measurement errors and related uncertainties is called the likelihood (i.e., the conditional probability of the measurements given the parameters). The model for the unknowns that reflects all of the uncertainty in the parameters without the information conveyed by the measurements is called the prior model (Beck and Arnold, 1977; Kaipio and Somersalo, 2004; Lee, 2004; Tan et al., 2006). The formal mechanism to combine new information (measurements) with previously available information (prior) is known as Bayes' theorem (Beck and Arnold, 1977; Kaipio and Somersalo, 2004; Lee, 2004; Tan et al., 2006). Therefore, the term Bayesian is often used to describe statistical inversion approaches based on the principles that (Kaipio and Somersalo, 2004): (i) all variables in the model are treated as random variables, (ii) the randomness describes the degree of information concerning their realization, which is coded in probability distributions, and (iii) the solution of the inverse problem is the posterior probability distribution from which point estimates and other statistics are computed.

This study aims at characterizing the unsaturated hydraulic and solute transport properties of variably saturated soils. Similar studies have been carried out in the past using both smallscale laboratory soil column experiments (Abbaspour et al., 2001, 2004; Kool et al., 1985; Parker et al., 1985) as well as for more elaborate field scale settings (Hosseini et al., 2011; Kohne et al., 2006; Si and Kachanoski, 2000; Vrugt et al., 2006), in which minimization of the maximum likelihood objective function was used for estimating the unknown parameters. Various studies have used stochastic methods for studying fluid flow and contaminant transport processes using synthetic experimental data (Franssen et al., 2003a, Fu and Gómez-Fernandez, 2009), including particle filters for real-time estimations (Franssen et al., 2003b; Li et al., 2012; Vrugt et al., 2013; Xu et al., 2013; Zhou et al., 2011). Additionally, Bayesian estimators have been used for estimating unsaturated soil hydraulic parameters (Diamantopoulos et al., 2012; Laloy et al., 2010).

The present work differs from other studies in the literature by considering the estimation of soil hydraulic and transport properties by means of a Bayesian estimator using observed data of the pressure head and outflow solute concentration obtained from a small-scale unsaturated soil column experiment. Selected unsaturated soil hydraulic and transport parameters affecting fluid flow and contaminant transport are estimated with a Markov Chain Monte Carlo (MCMC) method through implementation of the Metropolis-Hastings algorithm (Hastings, 1970; Kaipio and Somersalo, 2004; Lee, 2004; Metropolis et al., 1953; Tan et al., 2006). The Bayesian approach permits one to include a priori information available for the parameters, such as from previous experimental runs or other experimental setups, or even from theoretical predictions. 
The flow problem in our study is described in terms of the standard Richards equation assuming uniform variably-saturated flow model in a single-porosity system, and a two-region (dualporosity) type physical non-equilibrium model for transport (Šimůnek et al., 2003; van Genuchten and Wierenga, 1976).

The present study extends earlier work by Orlande et al. (2009) who had used only simulated data in the inverse analysis. For the results presented here, actual pressure head and solute concentration experimental measurements were collected in a small-scale laboratory soil column experiment and used to estimate the unsaturated soil hydraulic and transport parameters. We analyzed the sensitivity coefficients in order to examine which parameters can be estimated simultaneously. The accuracy of the Bayesian approach was also evaluated by reproducing the estimated unsaturated soil hydraulic parameters obtained in the earlier studies by Kool et al. (1985) and Parker et al. (1985) involving the use of cumulative flux measurements. Below we present the mathematical formulation for the physical problem considered here, the solution of the inverse problem, a description of the experimental procedure and the parameter estimation results.

\section{PHYSICAL PROBLEM AND MATHEMATICAL FORMULATION}

The physical problem considered here concerns the flow of water and a dissolved tracer through a vertical unsaturated laboratory soil column of length $L$, as shown in Figure 1. At the initial time $(t=0)$, the pressure head, $h_{i}(z)$, inside the soil column is assumed to vary linearly as a function of the position, $z$, in the column (but not necessarily following equilibrium conditions). For $t>0$, a tracer solution with known concentration, $c_{0}$, is injected at the upper end of the column at a constant flow rate, $q_{0}$. The column is connected at its bottom to a vacuum chamber with pressure control, thus making it possible to keep a constant pressure head, $h_{b}$, at the outflow boundary. Values of the pressure head and solute concentration are assumed to be uniform in each cross section.

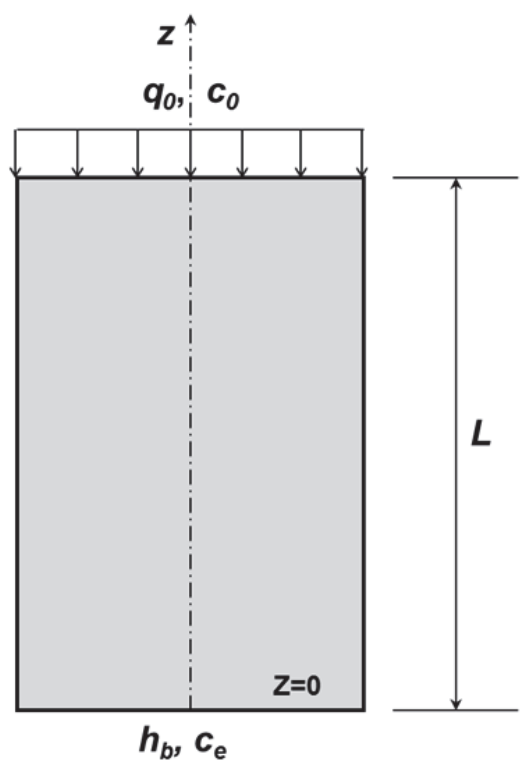

Fig. 1. Schematic of the one-dimensional flow and solute transport problem considered in this study.
The problem is simulated by assuming uniform flow as described by the standard Richards equation as follows:

$$
\frac{\partial \theta}{\partial t}=\frac{\partial}{\partial z}\left(K \frac{\partial h}{\partial z}+K\right) \quad \text { in } \quad 0 \leq z \leq L \text { and } t>0
$$

where $\theta$ is the volumetric water content $\left(L^{3} L^{-3}\right), h$ is the pressure head $(L), K$ is the hydraulic conductivity $\left(L T^{-1}\right), z$ is the distance from the bottom boundary upwards $(L)$, and $L$ is the length of the column $(L)$.

Equation (1) was solved subjected to the following boundary conditions:

$h=h_{b}$ at $z=0$, for $t>0$

$-\left(K \frac{\partial h}{\partial z}+K\right)=q_{0}$ at $z=L$, for $t>0$

and the initial condition:

$h=h_{i}(z)$ in $0<z<L$, at $t=0$

which varies linearly between the values

$h_{i}(0)=h_{0}-\Delta h \quad$ at $\quad z=0$

$h_{i}(L)=h_{0}+\Delta h \quad$ at $\quad z=L$

where $h_{0}$ is the initial pressure head in the middle of the column and $\Delta h$ some positive value of the pressure head difference between the middle of the column and its boundaries.

The relation between $\theta$ and $h$, as well as the hydraulic conductivity function, $K$, are described here by (van Genuchten, 1980):

$$
\begin{aligned}
& \theta(h)=\theta_{r}+\frac{\theta_{s}-\theta_{r}}{\left[1+|\alpha h|^{n}\right]^{m}} \\
& K\left(S_{e}\right)=K_{s} S_{e}^{l}\left[1-\left(1-S_{e}^{1 / m}\right)^{m}\right]^{2}
\end{aligned}
$$

where $\theta_{r}$ and $\theta_{s}$ are the residual and saturated water contents $\left(L^{3} L^{-3}\right)$, respectively, $K_{s}$ is the hydraulic conductivity at saturation $\left(L T^{-1}\right), \alpha\left(L^{-1}\right)$ and $n(-)$ are empirical shape parameters, $m=1-1 / n, l=0.5$ is a pore connectivity parameter, and $S_{e}$ is effective saturation given by

$$
S_{e}=\frac{\theta(h)-\theta_{r}}{\theta_{s}-\theta_{r}}
$$

A dual-porosity (two-region) type physical non-equilibrium model was used for the solute transport problem. By assuming linear equilibrium sorption, the equations governing transport in a variably-unsaturated soil are given by (van Genuchten and Wierenga, 1976):

$$
\begin{aligned}
& \frac{\partial}{\partial t}\left[\left(\theta_{m}+\rho_{b} f K_{d}\right) c_{m}\right]+\left[\theta_{i m}+\rho_{b}(1-f) K_{d}\right] \frac{\partial c_{i m}}{\partial t}= \\
& \frac{\partial}{\partial z}\left[\theta_{m} D_{m} \frac{\partial c_{m}}{\partial z}-q c_{m}\right]
\end{aligned}
$$


$\left[\theta_{i m}+\rho_{b}(1-f) K_{d}\right] \frac{\partial c_{i m}}{\partial t}=\alpha_{m}\left[c_{m}-c_{i m}\right] \quad$ in $\quad 0 \leq z \leq L \quad$ and

$t>0$

where the subscripts $m$ and $i m$ refer to mobile and immobile liquid regions, respectively, $c$ is the solute concentration $\left(M L^{-3}\right)$, $f$ defines the fraction of sorption sites in contact with mobile water $(-), \rho_{b}$ is the soil bulk density $\left(M L^{-3}\right), K_{d}$ is the distribution coefficient $\left(L^{-3} M\right), D_{m}$ is the dispersion coefficient $\left(L^{2} T^{-1}\right)$ and $\alpha_{m}$ is a mass transfer coefficient determining the solute transfer rate between the mobile and immobile regions $\left(T^{-1}\right)$. The dual-porosity formulation was used here since many tropical soils (often oxisols) of the type used in this study exhibit multi-modal pore- or particle-size distributions (e.g., Carducci et al., 2011; Sommer et al., 2003; Spohrer et al., 2006) favoring the existence of relatively immobile water pockets (Nkedi-Kizza et al., 1984; Melamed et al., 1994).

A third-type condition was used at the inflow boundary and a zero diffusive flux at the outflow boundary, that is,

$$
\begin{aligned}
& \frac{\partial c_{m}}{\partial z}=0 \quad \text { at } z=0 \text { for } t>0 \\
& -\theta_{m} D_{m} \frac{\partial c_{m}}{\partial z}+q_{0} c_{m}=q_{0} c_{0} \text { at } z=L \text { for } t>0
\end{aligned}
$$

The initial condition is of the form:

$c_{m}=c_{i m}=0$ in $0<z<L$ for $t=0$

The dispersion coefficient $D_{m}$ was defined following Bear's classical formulation with the tortuosity given by Millington and Quirk's model (Kohne et al., 2006) as follows:

$\theta_{m} D_{m}=D_{d} \frac{\theta_{m}^{10 / 3}}{\theta_{s}^{2}}+\lambda|q|$

where $D_{d}$ is the molecular diffusion coefficient $\left(L^{2} T^{-1}\right), \lambda$ is the dispersivity $(L)$, and $q$ is the volumetric fluid flux $\left(L T^{-1}\right)$ given by the Darcy-Buckingham law as follows:

$q=-K(h)\left(\frac{\partial h}{\partial z}+1\right)$

Following Nkedi-Kizza et al. (1984), we assumed that the fraction of sorption sites in contact with mobile water $(f)$ is the same as the ratio of the mobile water content $\left(\theta_{m}\right)$ to the total water content $(\theta)$, that is:

$f=\frac{\theta_{m}}{\theta}$

with

$$
\theta=\theta_{m}+\theta_{i m}
$$

By using Eqs. (12), Eqs. (8a, b) can be rewritten as:

$$
f \frac{\partial}{\partial t}\left(R \theta c_{m}\right)=\frac{\partial}{\partial z}\left[D^{*} \frac{\partial c_{m}}{\partial z}-q c_{m}\right]-\alpha_{m}\left[c_{m}-c_{i m}\right]
$$

$$
(1-f) R \theta \frac{\partial c_{i m}}{\partial t}=\alpha_{m}\left[c_{m}-c_{i m}\right]
$$

where

$D^{*}=\frac{D_{d} f^{10 / 3}}{\theta_{s}^{2}} \theta^{10 / 3}+\lambda|q|$

and $R=1+\frac{\rho_{b} K_{d}}{\theta}$

A unique feature of Eqs. $(13 a, b)$ is the fact that the fraction of immobile water (and hence also $f$ ) is assumed to be constant during transient variably-saturated flow conditions, in which the mobile and immobile water contents can vary in time and space. We believe that this assumption is more realistic, and certainly less restrictive, than having a constant immobile water content $\left(\theta_{i m}\right)$ in time, as assumed for example in the HYDRUS software package (Šimůnek et al., 2013), unless a dual-porosity type water flow exchange term is used between the mobile and immobile liquid regions. Limited experimental data (e.g., De Smedt and Wierenga, 1984; Maraqa et al., 1997) also support the assumption of having a constant immobile water fraction, $f$, independent of the degree of saturation. An additional advantage of the dual-porosity formulation used here is that the model simplifies immediately to the standard advectiondispersion equation when $f=1$. Hence, no a priori assumption is needed as to which formulation (the standard advection dispersion equation or the dual-porosity model) is most optimal for the transport problem being considered.

The forward problem, given by Equations (1) to (7), (9) and (13), with all model parameters, initial and boundary conditions known, was solved using an implicit finite volume discretization approach with the WUDS (Raithby and Torrance, 1974) interpolation scheme. The numerical solution of the forward problem was implemented in a Fortran code, which was verified against several reference solutions for different test-cases. Results presented below were obtained with the code developed in this work, by using converged grids.

\section{PARAMETER ESTIMATION}

The combined unsaturated flow and solute transport problem defined above involves the following vector of parameters:

$$
\mathbf{P}^{T}=\left[\mathbf{P}_{\text {Hydraulic }}^{T}, \mathbf{P}_{\text {Transport }}^{T}\right]
$$

which contains separate vectors of hydraulic and solute transport parameters as considered in our analysis:

$$
\begin{aligned}
& \mathbf{P}_{\text {Hydraulic }}^{T}=\left[K_{s}, \theta_{s}, \theta_{r}, \alpha, n, h_{0}, \Delta h\right] \\
& \mathbf{P}_{\text {Transport }}^{T}=\left[f,\left(\rho_{b} K_{d}\right), D_{d}, \lambda, \alpha_{m}\right]
\end{aligned}
$$

Note that the parameters $\rho_{b}$ and $K_{d}$ appear only in the form of a product in the transport problem, and hence cannot be treated independently. However, $\rho_{b}$ can be measured with relatively standard techniques, which would leave only $K_{d}$ as one of the unknowns in the vector of parameters.

Parameter estimation within the Bayesian framework is performed by treating all parameters in the mathematical formulation of the physical problem as random variables, with prior 
information coded in the form of probability distributions (Kaipio and Somersalo, 2004). Consider the vector of parameters appearing in the physical model formulation as $\mathbf{P}^{T} \equiv\left[P_{1}, P_{2}, \ldots, P_{N}\right]$, where $N$ is the number of parameters. Consider also that a vector of measurements $\mathbf{Y}$ is available for estimation of the parameters $\mathbf{P}$. Bayes' theorem can then be stated as (Kaipio and Somersalo, 2004; Lee, 2004; Tan et al., 2006):

$$
\pi_{\text {posterior }}(\mathbf{P})=\pi(\mathbf{P} \mid \mathbf{Y})=\frac{\pi(\mathbf{P}) \pi(\mathbf{Y} \mid \mathbf{P})}{\pi(\mathbf{Y})}
$$

where $\pi_{\text {posterior }}(\mathbf{P})$ is the posterior probability density, $\pi(\mathbf{P})$ is the prior density, $\pi(\mathbf{Y} \mid \mathbf{P})$ is the likelihood function, and $\pi(\mathbf{Y})$ is the marginal probability density of the measurements, which is a normalizing constant.

In our study we assumed that the measurement errors are Gaussian random variables, with zero means and constant variance, and that the measurement errors are additive and independent of the unknowns. With these assumptions, the likelihood function can be expressed as (Kaipio and Somersalo, 2004; Lee, 2004; Tan et al., 2006):

$$
\begin{aligned}
& \pi(\mathbf{Y} \mid \mathbf{P})=(2 \pi)^{-M / 2}|\mathbf{\Sigma}|^{-1 / 2} \exp \left\{-\frac{1}{2}[\mathbf{Y}-\mathbf{T}(\mathbf{P})]^{T} \boldsymbol{\Sigma}^{-1}[\mathbf{Y}-\right. \\
& \mathbf{T}(\mathbf{P})]\}
\end{aligned}
$$

where $M$ is the number of measurements, $\boldsymbol{\Sigma}$ is the covariance matrix of the measurement errors and $\mathbf{T}(\mathbf{P})$ is the solution of the direct problem obtained with the vector of parameters $\mathbf{P}$. We note that parameters estimated through maximization of Equation (16) are referred to as maximum likelihood estimates (Beck and Arnold, 1977).

The unknown parameters were estimated by using the Metropolis-Hastings algorithm for the Markov Chain Monte Carlo (MCMC) method (Hastings, 1970; Kaipio and Somersalo, 2004; Lee, 2004; Metropolis et al., 1953; Tan et al., 2006). Implementation of the Metropolis-Hastings algorithm starts with the selection of a proposal distribution $p\left(\mathbf{P}^{*}, \mathbf{P}^{(t-1)}\right)$, which is used to draw a new candidate state $\mathbf{P}^{*}$, given the current state $\mathbf{P}^{(t-1)}$ of the Markov chain. Once this moving distribution has been selected, the Metropolis-Hastings sampling algorithm can be implemented by repeating the following steps:

1. Sample a Candidate Point $\mathbf{P}^{*}$ from the proposal distribution $p\left(\mathbf{P}^{*}, \mathbf{P}^{(t-1)}\right)$.

2. Calculate the acceptance factor:

$$
\alpha=\min \left[1, \frac{\pi\left(\mathbf{P}^{*} \mid \mathbf{Y}\right) p\left(\mathbf{P}^{(t-1)}, \mathbf{P}^{*}\right)}{\pi\left(\mathbf{P}^{(t-1)} \mid \mathbf{Y}\right) p\left(\mathbf{P}^{*}, \mathbf{P}^{(t-1)}\right)}\right]
$$

3. Generate a random value $U$ which is uniformly distributed on $(0,1)$.

4. If $U \leq \alpha$, set $\mathbf{P}^{t}=\mathbf{P}^{*}$. Otherwise, set $\mathbf{P}^{t}=\mathbf{P}^{(t-1)}$.

5. Return to step 1 in order to generate the sequence $\left\{\mathbf{P}^{l}, \mathbf{P}^{2}, \ldots, \mathbf{P}^{n}\right\}$.

For more details on the theoretical aspects of the MetropolisHastings algorithm and MCMC methods, readers are referred to Kaipio and Somersalo (2004), Lee (2004) and Tan et al. (2006).

Proposal densities (Kaipio and Somersalo, 2004; Lee, 2004; Tan et al., 2006) for implementation of the Metropolis-Hastings algorithm were taken in this work as random walks, with Gaussian perturbations for the parameters with Gaussian priors, and with uniform perturbations for the parameters having uniform priors. Gaussian perturbations had zero means and standard deviations of $0.01 \%$ of the prior means. Uniform perturbations involved maximum steps of $0.5 \%$ of the parameter range established for the uniform prior. These proposal densities were selected based on numerical experiments.

Estimation of the unknown parameters must be preceded by an analysis of the sensitivity coefficients (Beck and Arnold, 1977; Özisik and Orlande, 2000). The sensitivity matrix is defined as:

$$
\mathbf{J}(\mathbf{P})=\left[\frac{\partial \mathbf{T}^{T}(\mathbf{P})}{\partial \mathbf{P}}\right]^{T}=\left[\begin{array}{ccccc}
\frac{\partial T_{1}}{\partial P_{1}} & \frac{\partial T_{1}}{\partial P_{2}} & \frac{\partial T_{1}}{\partial P_{3}} & \cdots & \frac{\partial T_{1}}{\partial P_{N}} \\
\frac{\partial T_{2}}{\partial P_{1}} & \frac{\partial T_{2}}{\partial P_{2}} & \frac{\partial T_{2}}{\partial P_{3}} & \cdots & \frac{\partial T_{2}}{\partial P_{N}} \\
\vdots & \vdots & \vdots & & \vdots \\
\frac{\partial T_{M}}{\partial P_{1}} & \frac{\partial T_{M}}{\partial P_{2}} & \frac{\partial T_{M}}{\partial P_{3}} & \cdots & \frac{\partial T_{M}}{\partial P_{N}}
\end{array}\right]
$$

where the sensitivity coefficients $J_{i j}=\frac{\partial T_{i}}{\partial P_{j}}$ give the sensitivity of the response of problem $T_{i}$ (i.e., the dependent variable being the solution of the direct problem) with respect to changes in the parameter $P_{j}$. A small value of $J_{i j}$ indicates that large changes in $P_{j}$ yield small changes in $T_{i}$. Estimation of parameter $P_{j}$ is typically very difficult in that case since very similar values of $T_{i}$ would be obtained for a wide range of $P_{j}$ values. When the sensitivity coefficients are small, $\left|\mathbf{J}^{T} \mathbf{J}\right| \approx 0$ and the inverse problem is illconditioned. Furthermore, $\left|\mathbf{J}^{T} \mathbf{J}\right|$ is null when a column of $\mathbf{J}$ becomes a linear combination of the other columns (Beck and Arnold, 1977; Özisik and Orlande, 2000). It is therefore desirable to have linearly independent sensitivity coefficients $J_{i j}$ with large magnitudes so that the parameter estimation problem is not very sensitive to measurement errors, and hence accurate parameter estimates can be obtained. A comparison of the magnitude of the sensitivity coefficients, as well as an analysis of possible linear dependencies, is more easily performed by using reduced sensitivity coefficients instead of the original ones. The reduced sensitivity coefficients are obtained by multiplying the original sensitivity coefficients, $J_{i j}$, by the parameters that they refer to. They have the same units as the measured variables, thus providing a basis for the comparisons. Since the sensitivity coefficients are functions of the model parameters in the present case, the parameter estimation problem is nonlinear and only a local analysis of the sensitivity coefficients is thus possible (Beck and Arnold, 1977; Özisik and Orlande, 2000). Sensitivity coefficients in our study were calculated using forward finite differences; convergence of this first order approximation was verified for all cases analyzed.

\section{EXPERIMENTAL PROCEDURE}

Laboratory soil column inflow/outflow experiments were carried out in order to obtain the data needed to estimate the unknown soil hydraulic and solute transport parameters of concern in our study, given by Eqs. (14). The apparatus (Figure 2) used for the experiment consisted mostly of equipment obtained from Soil Measurement Systems (Tucson, AZ), designed for unsaturated flow experiments. We used an acrylic column with an internal diameter of $5.1 \mathrm{~cm}$ and length of $7.3 \mathrm{~cm}$, packed with an undisturbed Brazilian Latosol soil sample, taken from a study area near Caetité, BA, Brazil. The bottom of the column was connected to a sealed vacuum chamber, which in turn was connected 


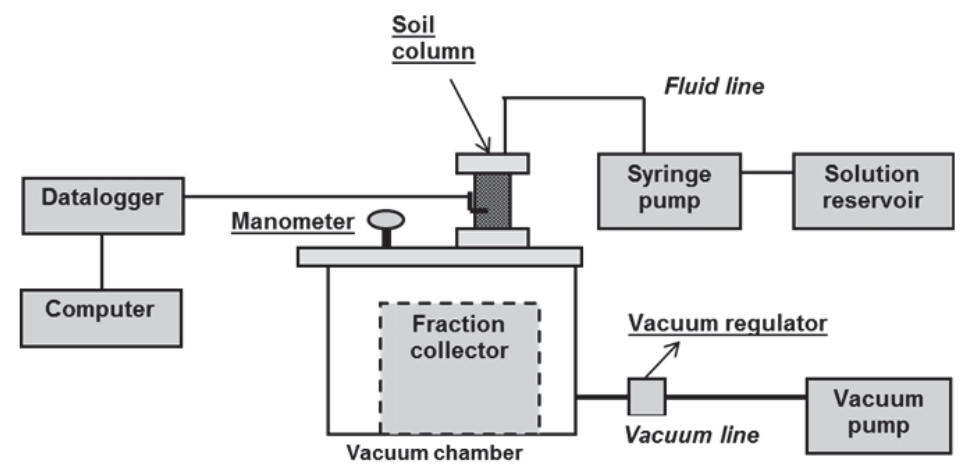

Fig. 2. Schematic of the experimental apparatus.

to a vacuum pump. The pressure inside the vacuum chamber was measured with a precision mercury U-tube manometer attached to the chamber. The pressure was controlled by a vacuum regulator, which allowed us to maintain a constant negative pressure head at the outflow boundary of the soil column.

Using a high-accuracy syringe pump, a potassium bromide $(\mathrm{KBr})$ solution with a concentration of $2.5 \mathrm{~g} / \mathrm{L}$ was injected from a reservoir to the top of the column, at a constant rate of $3.25 \times 10^{-4} \mathrm{~cm} / \mathrm{s}$. Variations in the pressure head in the center of the vertical column, at $z=3.5 \mathrm{~cm}$, were measured with a tensiometer attached to a pressure transducer and connected to a data logger and computer. A fraction collector, placed inside the vacuum chamber and containing a large number of sampling tubes, was used to collect the outflow fluid, thus allowing us to obtain a series of outflow rates and associated fluid concentrations.

The tensiometer halfway down the column consisted of a $10-\mathrm{mm}$ diameter, $60-\mathrm{mm}$ long acrylic tube. One of its ends was attached to a 6-mm diameter ceramic bar in direct contact with soil inside the column, while the other end was connected to a pressure transducer. The tensiometer was carefully installed such that outside air could not enter the column. Since transient pressure heads inside the column were recorded in terms of an electrical signal $(\mathrm{mV})$, the pressure transducer needed to be calibrated first. For this purpose, both the pressure transducer and the mercury manometer were connected to the vacuum chamber so that it was possible to record the voltages corresponding to a series of pressure head values.

$\mathrm{KBr}$ solute concentrations were assumed to be linearly related to the electric conductivity $(\mu \mathrm{S} / \mathrm{cm})$ of the outflow solution. This assumption was verified by measuring the electric conductivity of $\mathrm{KBr}$ solutions within the expected range of concentrations. It was then possible to immediately convert electric conductivities measured for each outflow sample, as well as of the inflow solution, into reduced solute concentrations, $c(t) / c_{0}$, with $c_{0}$ being the concentration of the injected solution. Based on values obtained during calibration, the standard deviations were 2.0 $\mathrm{cm}$ for the pressure head and $0.01(1 \%)$ for the normalized solute concentrations.

Relatively standard experiments (Dane and Topp, 2002) were carried out to obtain prior information about the soil bulk density, $\rho_{b}$, the saturated hydraulic conductivity, $K_{s}$, and the saturated water content, $\theta_{s}$. Mean values obtained with these measurements are listed in Table 1. Standard deviations of the measured data were approximately $1 \%$ of the mean values. The prior distributions for $\rho_{b}, K_{s}$, and $\theta_{s}$ were for these reasons assumed to have Gaussian distributions, centered at the mean values presented in Table 1 and with standard deviations of $1.0 \%$ of the mean values. Values of the residual water content $\theta_{r}$, and the water retention parameters $\alpha$ and $n$, were estimated from the measured soil textural distribution and the bulk density using the Rosetta pedotransfer functions (Schaap et al., 2001). Estimated values for these parameters are also shown in Table 1.

Table 1. Properties of the soil used in this study.

\begin{tabular}{l|c}
\hline Parameter & Value \\
\hline$\theta_{r}\left(\mathrm{~cm}^{3} / \mathrm{cm}^{3}\right)$ & 0.042 \\
\hline$\theta_{s}\left(\mathrm{~cm}^{3} / \mathrm{cm}^{3}\right)$ & 0.408 \\
\hline$\rho_{b}\left(\mathrm{~g} / \mathrm{cm}^{3}\right)$ & 1.637 \\
\hline$K_{s}(\mathrm{~cm} / \mathrm{s})$ & $9.37 \times 10^{-4}$ \\
\hline$\alpha\left(\mathrm{cm}^{-1}\right)$ & 0.040 \\
\hline$n(-)$ & 2.632 \\
\hline
\end{tabular}

\section{RESULTS AND DISCUSSIONS}

Before analysis of the infiltration/outflow parameter estimation problem considered in this study, we evaluated the implemented MCMC method by estimating unsaturated soil hydraulic parameters obtained with the one-step column outflow experiment described by Kool et al. (1985) and Parker et al. (1985). That experiment considered an undisturbed soil core of $5.40 \mathrm{~cm}$ diameter and $4.00 \mathrm{~cm}$ length (Parker et al., 1985). For times $t>0$, a constant pressure head of $10 \mathrm{~m}$ was applied at the top of the column, causing water stored in the soil column to move out of the medium, to be collected at the bottom of the column, which was maintained at atmospheric pressure (Parker et al., 1985). For the simulations and analysis of the sensitivity coefficients, the spatial domain was defined as a $3.95 \mathrm{~cm}$ long soil core placed over a $0.55 \mathrm{~cm}$ thick ceramic plate, resulting in a $L=4.50 \mathrm{~cm}$ long column consisting of two materials having different physical properties (the soil and the ceramic plate). The inverse problem dealt with cumulative outflow flux simulated measurements for the estimation of hydraulic parameters of the soil. In order to avoid an "inverse crime", as explained by Kaipio and Somersalo (2007), the one-step outflow experiment was simulated with the HYDRUS-1D code (Šimůnek et al., 2013) to generate the simulated data using a different mesh from the finite volume numerical solution we used for the forward problem. The finite volume solution for the forward problem was used for analysis of the sensitivity coefficients based on the parameter values shown in Table 2 (Kool et al., 1985; Parker et al., 1985), as well as for the parameter estimation problem using the simulated measurements. The simulated measurements contained additive, uncorrelated Gaussian errors, with zero mean and a constant standard deviation of $2 \%$ of the maximum cumulative flux. 
Bayesian estimation of the hydraulic and solute transport properties of a small-scale unsaturated soil column

Table 2. Parameter values used for analysis of the sensitivity coefficients in the experiment of Parker et al. (1985).

\begin{tabular}{l|c}
\hline Parameter & Value \\
\hline Residual water content of the soil core & $\theta_{r, \text { soil }}=0.161$ \\
\hline Saturated water content of the soil core & $\theta_{s, \text { soil }}=0.388$ \\
\hline Saturated hydraulic conductivity of the soil core & $K_{s, \text { soil }}=1.5 \times 10^{-3} \mathrm{~cm} / \mathrm{s}$ \\
\hline van Genuchten $\alpha$ parameter of the soil core & $\alpha_{\text {soil }}=0.033 \mathrm{~cm}^{-1}$ \\
\hline van Genuchten $n$ parameter of the soil core & $n_{\text {soil }}=1.387$ \\
\hline Residual water content of the ceramic plate & $\theta_{r, \text { plate }}=0.0$ \\
\hline Saturated water content of the ceramic plate & $\theta_{s, \text { plate }}=1.0$ \\
\hline Saturated hydraulic conductivity of the ceramic plate & $K_{s, \text { plate }}=8.7 \times 10^{-7} \mathrm{~cm}^{-} \mathrm{s}$ \\
\hline van Genuchten $\alpha$ parameter of the ceramic plate & $\alpha_{\text {plate }}=1.0 \times 10^{-20} \mathrm{~cm}^{-1}$ \\
\hline van Genuchten $n$ parameter of the ceramic plate & $n_{\text {plate }}=1.1$ \\
\hline
\end{tabular}

Variations in the cumulative outflow, as well as in the reduced sensitivity coefficients, are presented in Figure 3.

Figure $3 \mathrm{a}$ shows that the sensitivity coefficients had very small values compared to the variations in the cumulative outflow. Figure $3 \mathrm{~b}$ provides a close-up of the reduced sensitivity coefficients versus time. The variations are approximately three orders of magnitude smaller than the cumulative outflow rates, meaning that variations in the hydraulic parameters have very little effect on the cumulative outflow. The results also indicate a linear dependence between the parameters $\theta_{r}$ and $\theta_{s}$, as well as among the parameters $K_{s}, \alpha$ and $n$. Since the values of $\theta_{s}$ and $K_{s}$ were directly measured by Parker et al. (1985), we defined their a priori distributions to be Gaussian, centered on the values obtained for each parameter. Nevertheless, the parameters $\alpha$ and $n$ were found to be linearly dependent and their curves for the sensitivity coefficients were coincident. This linear dependency made it necessary to fix an informative a priori distribution for either $\alpha$ and $n$ in order to make the estimation possible. Van Genuchten (1978) previously showed a graphical procedure to obtain the coefficient $n$ from observed water content data, independently from $\alpha$. Other studies (e.g., Leij et al., 1997; van Genuchten and Nielsen, 1985; Yates et al., 1992) showed that for a given soil the values of $\alpha$ and $n$ generally can be obtained independently. For these reasons, we assumed a Gaussian a priori distribution for $n$, centered on the value obtained by Parker et al. (1985). Since $\theta_{s}, K_{s}$, and $n$ could be considered as known parameters, their prior distributions were defined with a small standard deviation. For the parameters $\theta_{r}$ and $\alpha$, the a priori conditions were defined as uniform distributions defined from the initial values used in Parker et al. (1985). All of the prior distributions are listed in Table 3 . The parameter values estimated with the MCMC method are presented in Table 4, including their respective confidence intervals, and compared to the values obtained by Parker et al. (1985). Notice that the values obtained by Parker et al. (1985) are inside the confidence intervals obtained in our study. Figure 4 shows a comparison between the experimental cumulative outflow curve and the outflow curve obtained with the estimated MCMC parameter values. Results indicate excellent agreement between the experimental and estimated curves, with small and practically uncorrelated residuals (difference between experimental and estimated values).

We next focus on the inverse analysis using the experimental setup described earlier (Fig. 2). The following measurements were used to estimate the sensitivity coefficients: (i) transient variations in the pressure head halfway down the column; (ii) volumetric fluid fluxes at the outlet of the column; and (iii) solute concentrations of the outflowing fluid. For the analysis of the sensitivity coefficients with respect to the unknown hydraulic and solute transport parameters, we used the values presented in Table 5. These values were selected based on direct measurements (see Table 1) and on expected values of the parameters.

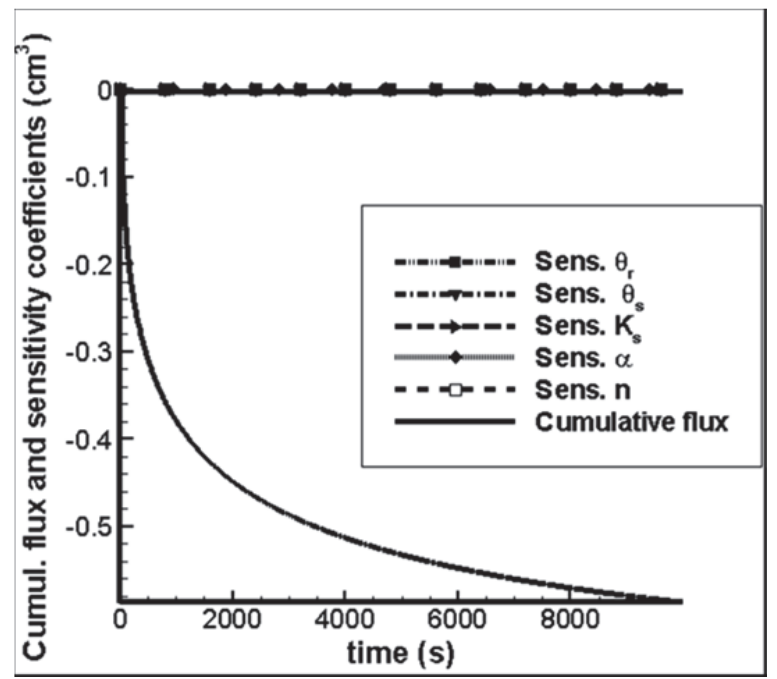

(a)

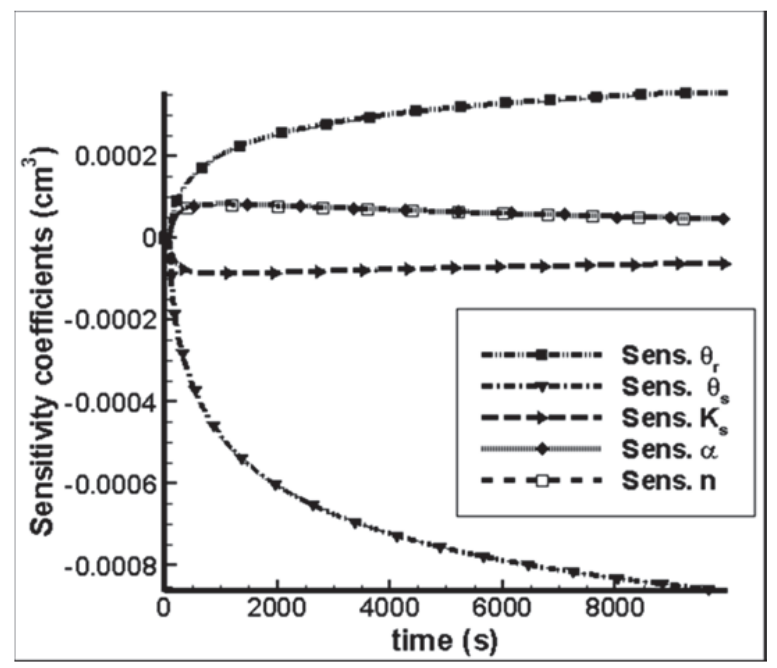

(b)

Fig 3. Variations in the cumulative outflow flux and its sensitivity coefficients (a), and close-up of the variations in the sensitivity coefficients with respect to the hydraulic parameters (b) in the experiment of Parker et al. (1985). 


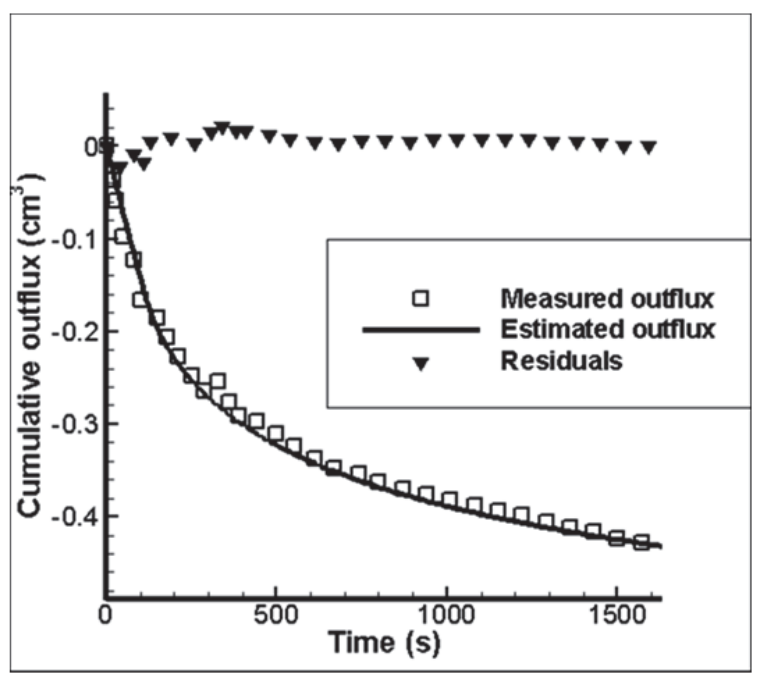

Fig. 4. Variations in time of the simulated measurements, estimated cumulative flux and the residuals of the experiment by Parker et al. (1985).

Table 3. Prior distributions considered for the MCMC evaluation of the experiment of Parker et al. (1985).

\begin{tabular}{|c|c|c|}
\hline Parameter & $\begin{array}{c}\text { A priori } \\
\text { Distributions } \\
\text { (MCMC) } \\
\end{array}$ & Distribution data \\
\hline$\theta_{r}$ & Uniform & $\begin{array}{c}\text { Interval: }\left(0.6 \bar{\theta}_{r}, 1.4 \bar{\theta}_{r}\right) \\
\bar{\theta}_{r}=0.200\end{array}$ \\
\hline$\theta_{s}$ & Gaussian & $\begin{array}{c}\quad \text { Mean: } \bar{\theta}_{s}=0.388 \\
\text { Standard Deviation: } 0.01 \bar{\theta}_{s}\end{array}$ \\
\hline$K_{s}$ & Gaussian & $\begin{array}{l}\text { Mean: } \bar{K}_{s}=1.5 \times 10^{-3} \mathrm{~cm} / \mathrm{s} \\
\text { Standard Deviation: } 0.01 \bar{K}_{s}\end{array}$ \\
\hline$\alpha$ & Uniform & $\begin{array}{c}\text { Interval: }(0.6 \bar{\alpha}, 1.4 \bar{\alpha}) \mathrm{cm}^{-1} \\
\bar{\alpha}=2.5 \times 10^{-2} \mathrm{~cm}^{-1}\end{array}$ \\
\hline$n$ & Gaussian & $\begin{array}{c}\text { Mean: } \bar{n}=1.387 \\
\text { Standard Deviation: } 0.01 \bar{n}\end{array}$ \\
\hline
\end{tabular}

Figure 5a shows transient variations in the pressure head in the middle of the soil column and the reduced sensitivity coefficients with respect to all the hydraulic and solute transport parameters, using the values presented in Table 5.

Note that the reduced sensitivity coefficients are all practically zero relative to the pressure head values. The reduced sensitivity coefficients with respect to the hydraulic parameters are about four orders of magnitude smaller than the pressure head, as illustrated in Figure $5 \mathrm{~b}$, which is a magnification of Figure $5 \mathrm{a}$ within the region of interest for analysis of the sensitivity coefficients. An analysis of Figure 5b reveals a linear dependence among the sensitivity coefficients with respect to $K_{s}, \alpha$ and $n$, as well as between $\theta_{r}$ and $\theta_{s}$. The sensitivity coefficients with respect to $h_{0}$ and $\Delta h$ were practically zero. Figure $5 \mathrm{~b}$ also shows that the sensitivity coefficients become constant when steady state conditions are approached. For the transport parameters, the sensitivity coefficients were zero, as shown in Figure 5c. This was expected since the transport parameters do not appear in the formulation of the flow problem given by Equations (1)-(4). The reverse situation, however, is the case in that solute transport information can improve the estimation of soil hydraulic parameters.

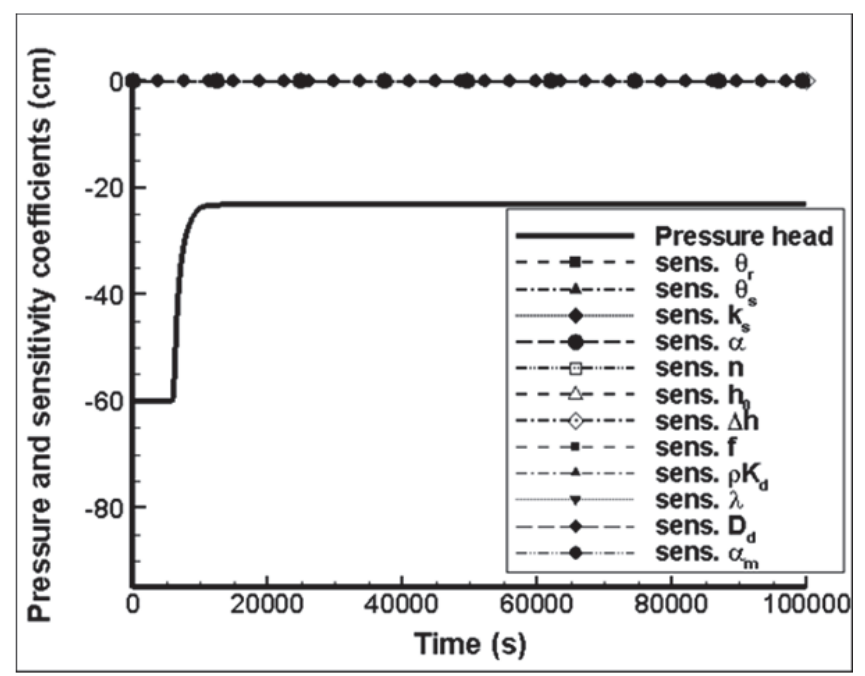

(a)

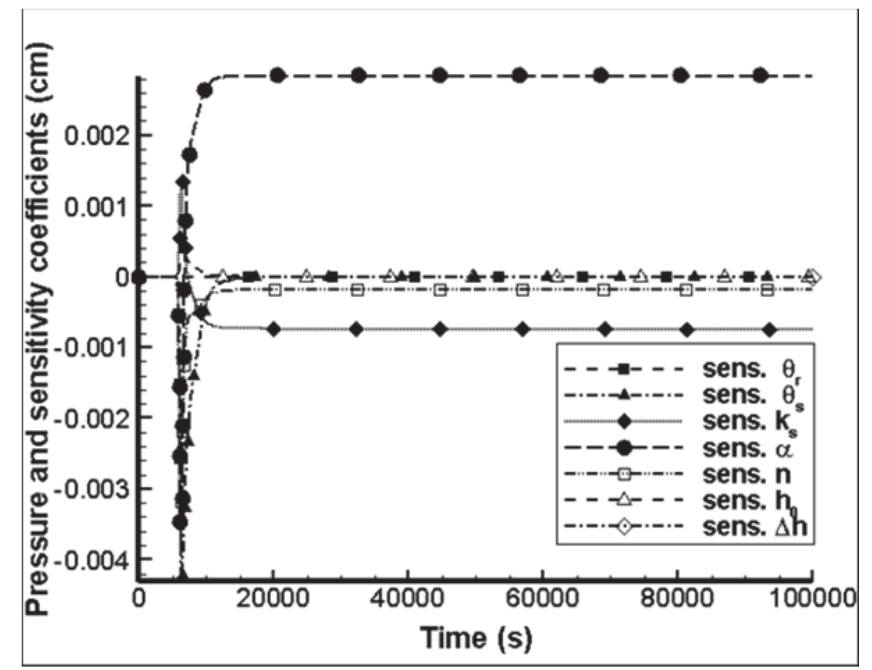

(b)

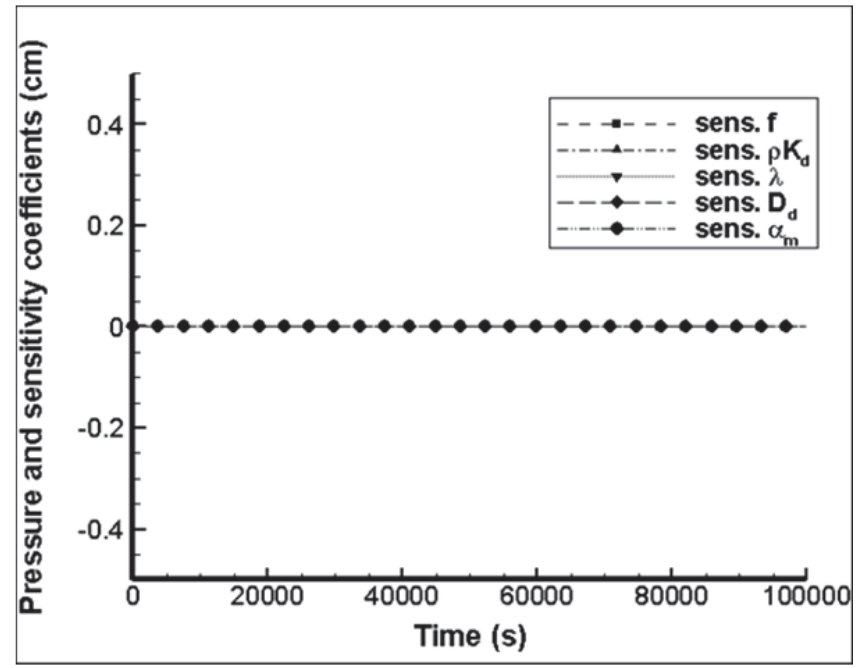

(c)

Fig. 5. Variations in the pressure head in the middle of the column and in its sensitivity coefficients (a), and close-ups of variations in the sensitivity coefficients with respect to the hydraulic (b) and transport (c) parameters. 
Table 4. Evaluation of the MCMC analysis of the experiment of Parker et al. (1985).

\begin{tabular}{l|c|c|c}
\hline Parameter & Values estimated by Parker et al. (1985) & Estimated values using MCMC & $\begin{array}{c}99 \% \text { confidence intervals } \\
\text { (MCMC) }\end{array}$ \\
\hline$\theta_{r}$ & 0.161 & 0.163 & $(0.162,0.164)$ \\
\hline$\theta_{s}$ & 0.388 & 0.388 & $(0.385,0.391)$ \\
\hline$K_{s}(\mathrm{~cm} / \mathrm{s})$ & $1.500 \times 10^{-3}$ & $1.503 \times 10^{-3}$ & $\left(1.500 \times 10^{-3}, 1.506 \times 10^{-3}\right)$ \\
\hline$\alpha\left(\mathrm{cm}^{-1}\right)$ & $3.350 \times 10^{-2}$ & $2.990 \times 10^{-2}$ & $\left(2.90 \times 10^{-2}, 3.10 \times 10^{-2}\right)$ \\
\hline$n$ & 1.387 & 1.388 & $(1.386,1.390)$ \\
\hline
\end{tabular}

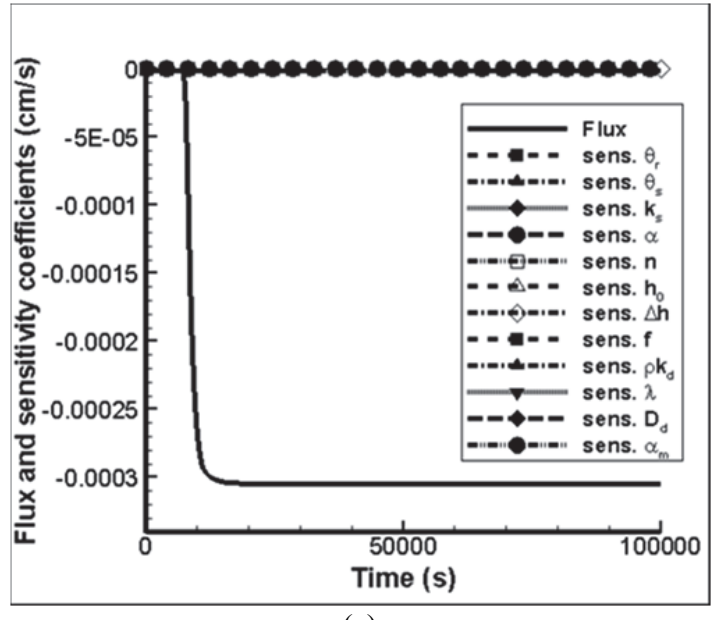

(a)

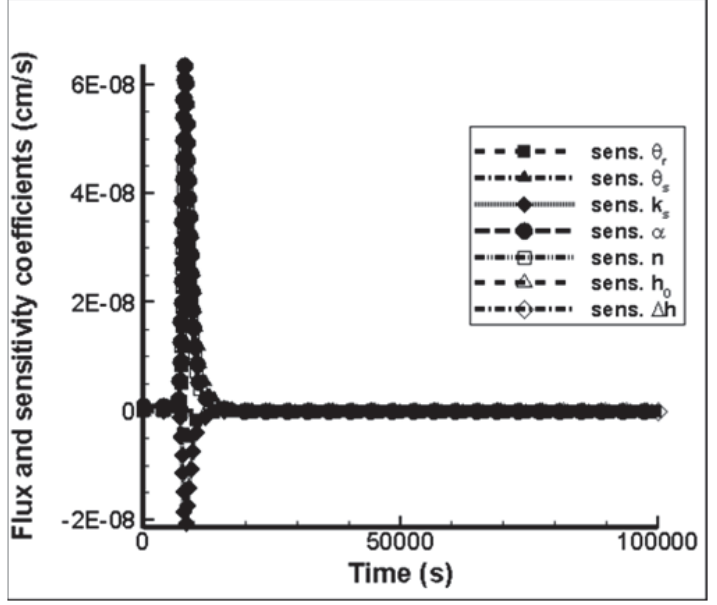

(b)

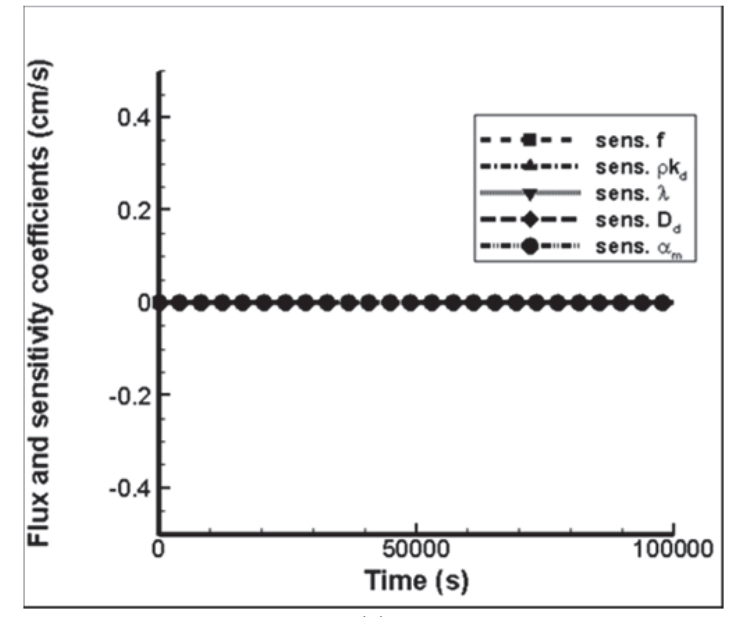

(c)

Fig. 6. Variations in the fluid flux exiting the column and its sensitivity coefficients (a), and close-ups of variations in the sensitivity coefficients with respect to the hydraulic (b) and transport (c) parameters.

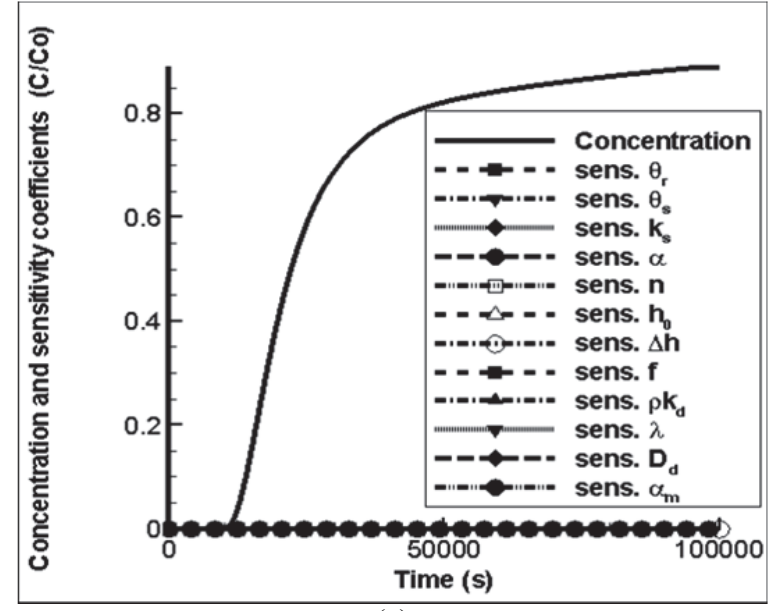

(a)

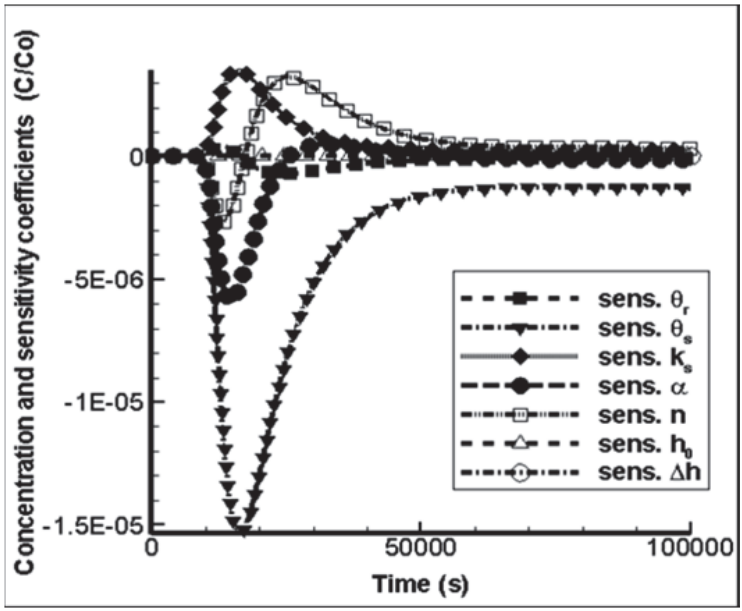

(b)

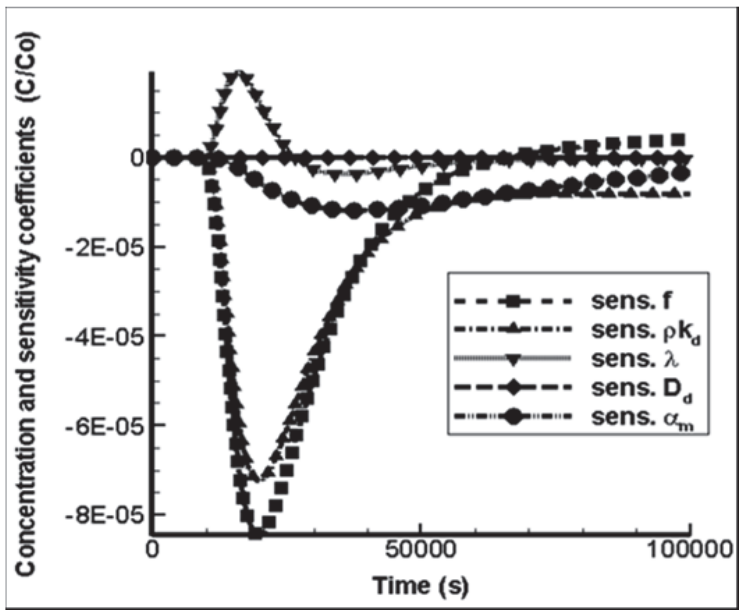

(c)

Fig. 7. Variations in the solute concentration of the fluid exiting the soil columns and its sensitivity coefficients (a), and magnifications of variations in the sensitivity coefficients with respect to the hydraulic (b) and transport (c) parameters. 
Variations in the volumetric fluid flux exiting the column, as well as its sensitivity coefficients, are presented in Figure 6a. The parameter values listed in Table 5 were also used in this analysis. Similarly to the pressure head measurements examined in Figures 5, the sensitivity coefficients of the fluid flux are practically zero. Figure $6 \mathrm{~b}$ shows that the sensitivity coefficients of the hydraulic parameters are again four orders of magnitude smaller than the measured values for our test case.

Table 5. Parameter values used for the analysis of the sensitivity coefficients.

\begin{tabular}{l|c}
\hline Parameter & Value \\
\hline Column height & $L=7.3 \mathrm{~cm}$ \\
\hline Infiltration flux & $q_{0}=3.050 \times 10^{-4} \mathrm{~cm} / \mathrm{s}$ \\
\hline Head at the bottom of the column & $h_{b}=-60 \mathrm{~cm}$ \\
\hline Constant initial head in the column & $h_{i}=-60 \mathrm{~cm}$ \\
\hline Residual water content & $\theta_{r}=0.042$ \\
\hline Saturated water content & $\theta_{s}=0.408$ \\
\hline Saturated hydraulic conductivity & $K_{s}=9.730 \times 10^{-4} \mathrm{~cm} / \mathrm{s}$ \\
\hline van Genuchten $\alpha$ parameter & $\alpha=0.040 \mathrm{~cm}^{-1}$ \\
\hline van Genuchten $n$ parameter & $n=2.632$ \\
\hline Fraction of sorption sites in contact \\
with mobile water & $f=0.500$ \\
\hline Soil bulk density & $\rho_{b}=1.637 \mathrm{~g} / \mathrm{cm}^{3}$ \\
\hline Distribution coefficient & $K_{d}=1.0 \mathrm{~cm}^{3} / \mathrm{g}$ \\
\hline Dispersivity & $\lambda=1.0 \mathrm{~cm}^{-5}$ \\
\hline Distribution coefficient & $D_{d}=1.0 \times 10^{-5} \mathrm{~cm}^{2} / \mathrm{s}$ \\
\hline Mass transfer coefficient & $\alpha_{m}=1.0 \times 10^{-5} \mathrm{~s}^{-1}$ \\
\hline Normalized initial concentration & $c_{i}=0.0$ \\
\hline $\begin{array}{l}\text { Normalized concentration of the } \\
\text { injected tracer }\end{array}$ & $c_{0}=1.0$ \\
\hline
\end{tabular}

Additionally, the sensitivity coefficients with respect to the hydraulic parameters are all linearly dependent, while those with respect to the transport parameters are all zero, as can be observed in Figure 6c. This indicates that measurements of the fluid flux did not contribute much useful information for estimation of the unknown hydraulic and transport parameters.

Variations in the solute concentrations of the outflow, as well as its sensitivity coefficients, are presented in Figure $7 \mathrm{a}$ for the parameter values specified in Table 5. Once again, the reduced sensitivity coefficients are four orders of magnitude smaller than the solute concentrations. The sensitivity coefficients with respect to the hydraulic parameters in Figure $7 \mathrm{~b}$ show that $\alpha$ and $n$ are linearly dependent, as well as $\theta_{s}$ and $K_{s}$. The sensitivity coefficients are zero for $h_{0}$ and $\Delta h$. Figure $7 \mathrm{c}$ further shows that the transport parameters $f,\left(\rho_{b} K_{d}\right), \lambda$ and $n$ are linearly independent, while the sensitivity coefficient is zero for the dispersion coefficient, $D_{d}$. The latter is due to the dominant effects of hydrodynamic dispersion in the dispersion coefficient as compared to molecular diffusion (Equation 10).

The above analysis revealed that the parameter estimation problem considered in this study is difficult due to small values and linear dependencies of the sensitivity coefficients. Only measurements of the pressure head in the middle of the column and of the outflow solute concentration provided meaningful information for estimation of several parameters.

The Bayesian estimation approach is capable of dealing with these difficulties by using informative prior distributions for the parameters that could be independently measured or estimated. The values of $\theta_{s}$ and $K_{s}$ were experimentally measured, as discussed above. The initial pressure head at the observation position point, $h_{0}$, was read by the tensiometer situated in the soil column, while the pressure head difference, $\Delta h$, was obtained from the initial pressures at the surfaces of the column. It was thus possible to estimate the vector of hydraulic parameters assuming uniform or Gaussian prior distributions, according to the quality of the a priori information available for each parameter. Since $\theta_{s}, K_{s}, h_{0}$ and $\Delta h$ were directly measured, Gaussian prior distributions were adopted for these parameters. For $\theta_{r}, \alpha$ and $n$, prior uniform distributions were used. For $D_{d}$, with practically null sensitivity coefficient, a Gaussian prior distribution was defined based on the known range of effective diffusion coefficients for unsaturated soils (e.g., Shackelford, 1991).

The estimation process was carried out in two steps. In the first step, the hydraulic parameters $\mathbf{P}_{\text {Hydraulic }}^{T}=\left[\theta_{r}, \theta_{s}, K_{s}, \alpha, n, h_{0}, \Delta h\right]$ were estimated by using the measured data of the pressure head in the middle of the column. In the second step we used estimates for the flow parameters as prior information for the coupled flow-transport problem in which the transport parameters $\mathbf{P}_{\text {Transport }}^{T}=\left[f,\left(\rho_{b} K_{d}\right), D_{d}, \lambda, \alpha_{m}\right]$ were estimated from the measured concentration data of the outflow and the pressure heads in the middle of the column. Since the hydraulic parameters were treated as random in the second step, they were also allowed to vary in the Markov chain, in accordance with their prior distributions.

The prior distributions used for the hydraulic parameters in the first step are presented in Table 6 . In order to estimate the hydraulic parameters, pressure head measurements in the middle of the column were considered until a time equal to $3300 \mathrm{~s}$ for the solution of the inverse problem, with experimental errors assumed to have additive, uncorrelated Gaussian distributions with zero mean and standard deviation corresponding to $5 \%$ of the difference between the minimum and maximum measured values ( $2.0 \mathrm{~cm}$, for our example). Table 7 lists the values estimated for each hydraulic parameter, while Equation (19) presents the obtained correlation matrix, where strong correlations among some parameters can be observed, as expected.

$\operatorname{cor}\left(\theta_{r}, \theta_{s}, k_{s}, \alpha, n, h_{0}, \Delta h\right)=\left[\begin{array}{ccccccc}1 & -0.1622 & -0.1241 & -0.0395 & 0.2029 & -0.1136 & -0.0018 \\ -0.1622 & 1 & 0.5484 & 0.6076 & -0.3273 & 0.3412 & -0.1045 \\ -0.1241 & 0.5484 & 1 & 0.9169 & -0.8413 & 0.1271 & -0.3321 \\ -0.0395 & 0.6076 & 0.9169 & 1 & -0.5649 & 0.4137 & -0.2272 \\ 0.2029 & -0.3273 & -0.8413 & -0.5649 & 1 & 0.3331 & 0.3979 \\ -0.1136 & 0.3412 & 0.1271 & 0.4137 & 0.3331 & 1 & 0.1959 \\ -0.0018 & -0.1045 & -0.3321 & -0.2272 & 0.3979 & 0.1959 & 1\end{array}\right]$


Table 6. Prior distributions of the hydraulic parameters used in the first step.

\begin{tabular}{l|c|c}
\hline Parameter & Distribution & Distribution information \\
\hline$\theta_{r}$ & Uniform & $\underline{\text { Interval: }\left(0, \bar{\theta}_{s}\right)}$ \\
\hline$\theta_{s}$ & Gaussian & $\underline{\underline{\text { Mean: }} \bar{\theta}_{s}=0.408\left(\mathrm{~cm}^{3} / \mathrm{cm}^{3}\right)}$ \\
& & $\underline{\text { Standard deviation: } 0.01 \bar{\theta}_{s}\left(\mathrm{~cm}^{3} / \mathrm{cm}^{3}\right)}$ \\
\hline$K_{s}$ & Gaussian & $\underline{\text { Mean: } \bar{K}_{s}=7.0 \times 10^{-4} \mathrm{~cm} / \mathrm{s}}$ \\
\hline$\alpha$ & Utandard deviation: $0.2 \bar{K}_{s}$ \\
\hline$n$ & Uniform & $\underline{\text { Interval: }(0.8 \bar{\alpha}, 1.2 \bar{\alpha}) \mathrm{cm}^{-1}}$ \\
\hline $\bar{\alpha}=0.018 \mathrm{~cm}^{-1}$
\end{tabular}

Table 7. Estimated values of the unsaturated soil hydraulic parameters.

\begin{tabular}{l|c|c}
\hline Parameter & Mean & $99 \%$ confidence interval \\
\hline$\theta_{r}\left(\mathrm{~cm}^{3} / \mathrm{cm}^{3}\right)$ & $0.118 \times 10^{-2}$ & $\left(0,0.366 \times 10^{-2}\right)$ \\
\hline$\theta_{s}\left(\mathrm{~cm}^{3} / \mathrm{cm}^{3}\right)$ & 0.409 & $(0.408,0.410)$ \\
\hline$K_{s}(\mathrm{~cm} / \mathrm{s})$ & $1.07 \times 10^{-3}$ & $\left(0.956 \times 10^{-3}, 1.196 \times 10^{-3}\right)$ \\
\hline$\alpha\left(\mathrm{cm}^{-1}\right)$ & $2.107 \times 10^{-2}$ & $\left(2.009 \times 10^{-2}, 2.204 \times 10^{-2}\right)$ \\
\hline$n(-)$ & 1.236 & $(1.228,1.243)$ \\
\hline$h_{0}(\mathrm{~cm})$ & -59.308 & $(-59.536,-59.081)$ \\
\hline$\Delta h(\mathrm{~cm})$ & 3.523 & $(3.516,3.530)$ \\
\hline
\end{tabular}

With the mean values of the parameters as presented in Table 7, it was possible to simulate the variations in the pressure head halfway down the column using Equations (1)-(4). Figure 8a shows a comparison of the experimental and simulated curves for the pressure head inside the soil column. The simulated curve generally falls within the range of the experimental errors, except at the very beginning of the experiment when the effects of the estimation of the initial pressure head and its gradient are more significant. Figure $8 \mathrm{~b}$ further shows that the pressure head residuals (i.e. the difference between experimental and estimated values), although small, are correlated, which indicates that the mathematical model used to describe the fluid flow problem did not fully represent the physics of the problem.

Figure 9 presents the number of accepted states and values of the hydraulic parameters at each state of the Markov chain. The Markov chain was generated with 50,000 states, considering the last 30,000 states for computation of the statistics. The convergence of the chain was tested by calculating the mean values of the parameters in different ranges inside the interval considered for the calculations (Geweke, 1992). The chain converged for all parameters, despite the linear dependence of $\theta_{s}$ and $K_{s}$, with respect to $\theta_{r}$ and $n$, respectively. The acceptance ratio of the Markov chain was approximately $14 \%$.

In the second step, the measured pressure head and solute concentration data were used to estimate the hydraulic and transport parameters of the combined vector of parameters $\mathbf{P}^{T}=\left[\mathbf{P}_{\text {Hydraulic }}^{T}, \mathbf{P}_{\text {Transport }}^{T}\right]$. The estimated values of the

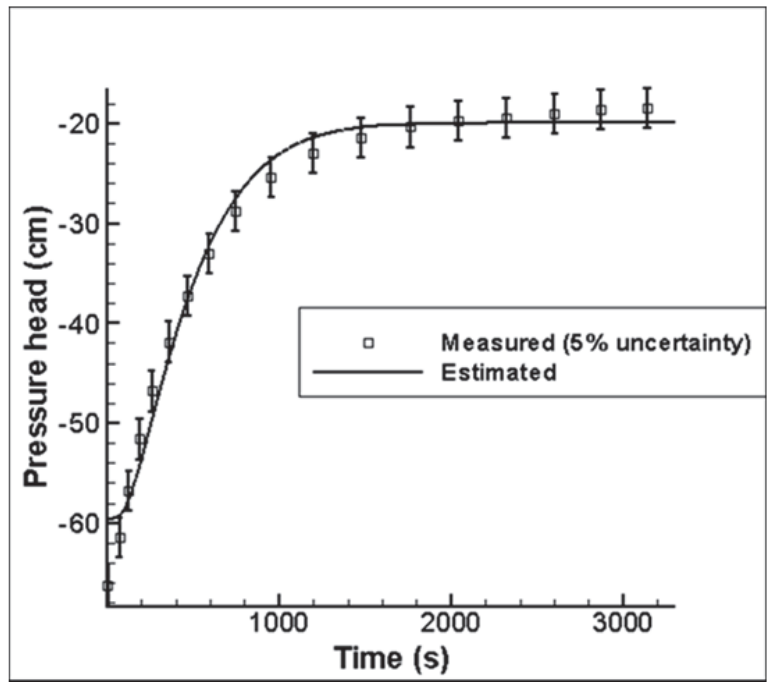

(a)

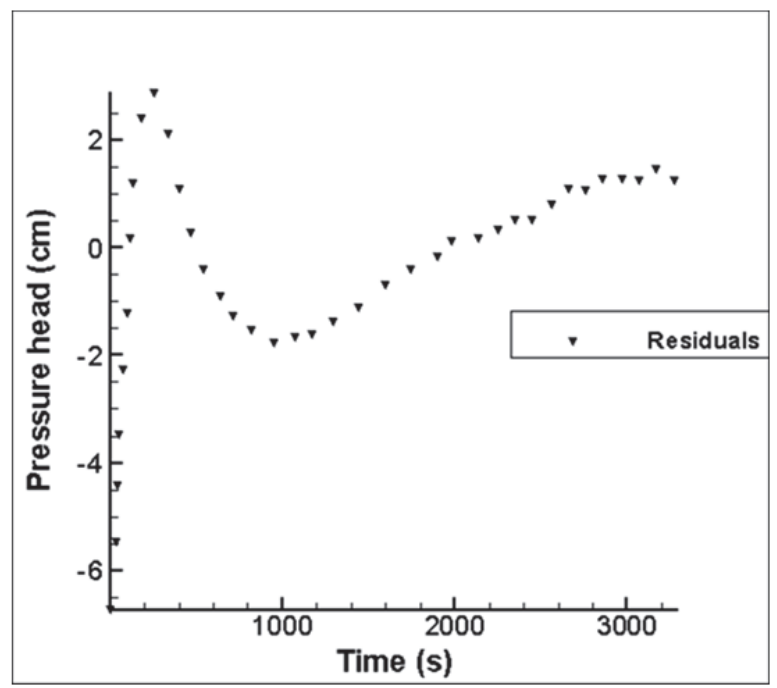

(b)

Fig. 8. Comparison of experimental and simulated curves for the pressure head halfway down the column (a) and the residuals (b).

hydraulic parameters of step 1 were then used as prior information with Gaussian distributions centered at the mean values presented in Table 7 and with the covariance resulting from the estimation in step 1. The prior distributions used for the transport parameters are defined in Table 8 . The value of the product $\rho_{b} K_{d}$ of the distribution coefficient was assumed to be very small, that is, $\mathrm{KBr}$ was taken approximately as a conservative tracer (Equation 13d), which is characteristic of soils such as the one used in this work at neutral $\mathrm{pH}$ (Goldberg and Kabengi, 2010).

The estimated means of the marginal posterior distributions for the transport parameters are presented in Table 9, together with their $99 \%$ confidence intervals. With the mean values for the parameters it was possible to compare the experimental and theoretical solute concentration curves of the column outflow, as seen in Figure 10a. Excellent agreement was obtained for the two curves. Although correlated, the concentration residuals are of the same order as the measurement uncertainties, as shown by Figure 10b. 


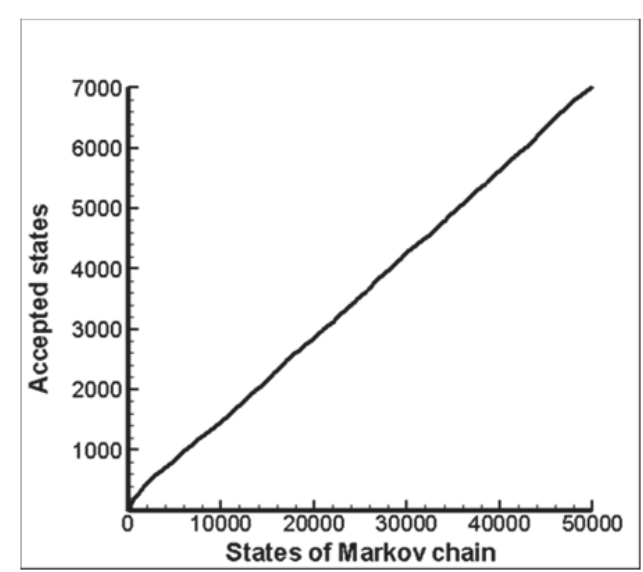

(a)

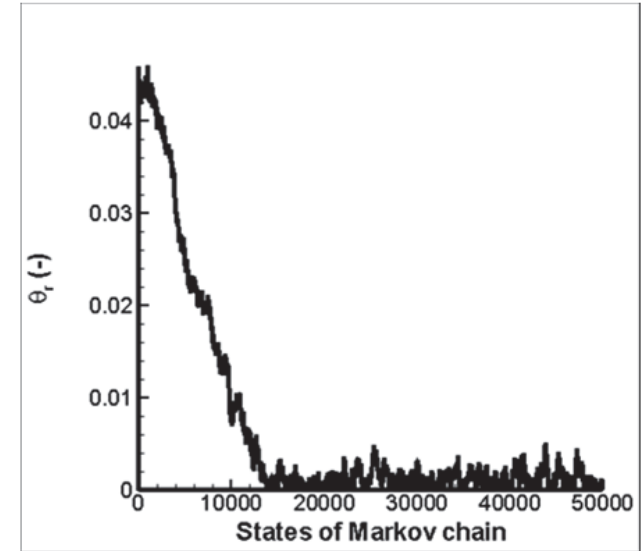

(b)

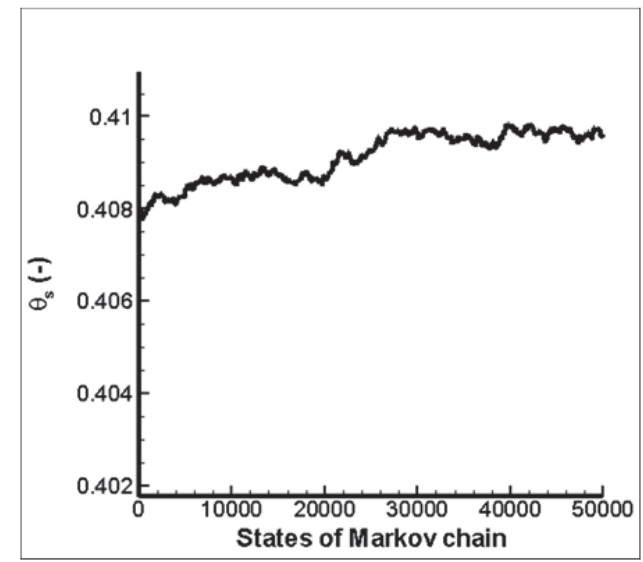

(c)

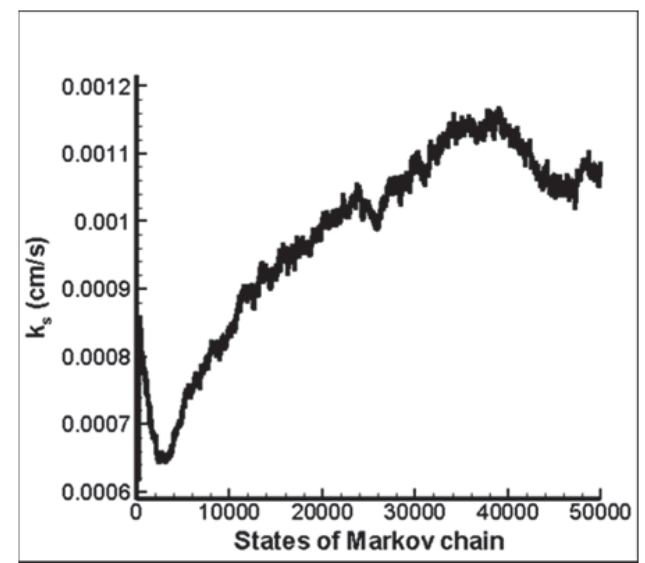

(d)

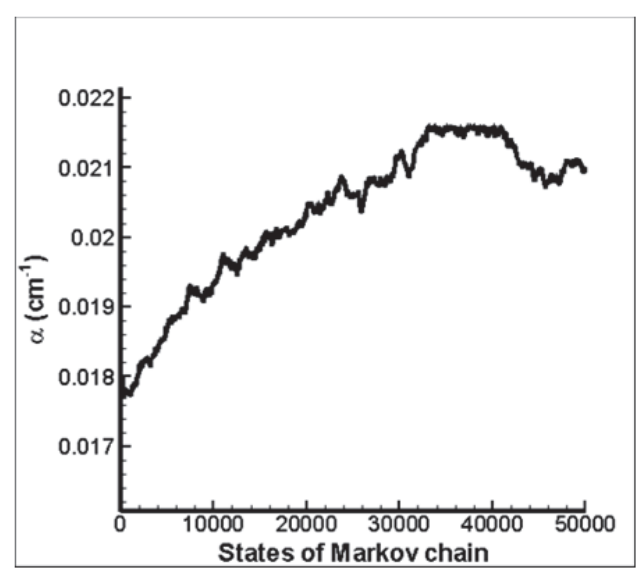

(e)

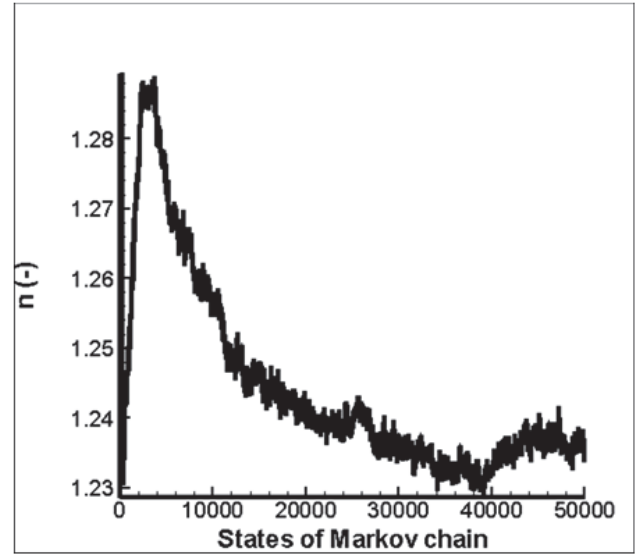

(f)

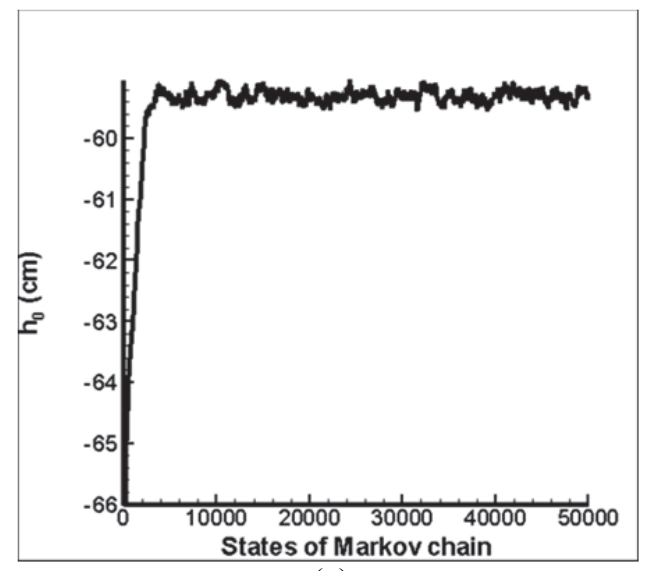

(g)

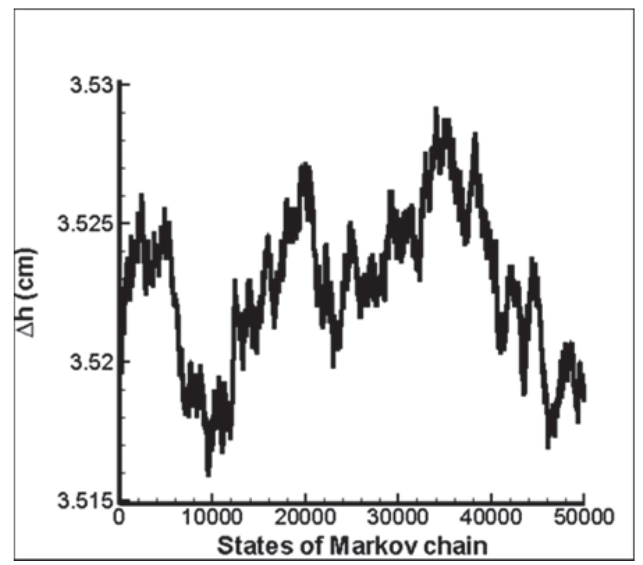

(h)

Fig. 9. States of the Markov chain for the unsaturated soil hydraulic parameters: (a) accepted states, (b) $\theta_{r}$, (c) $\theta_{s}$, (d) $K_{s}$, (e) $\alpha$, (f) $n$, (g) $h_{0}$, and (h) $\Delta h$. 


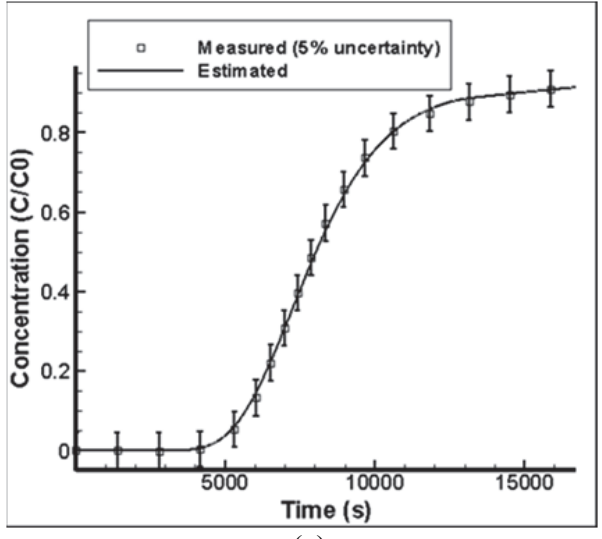

(a)

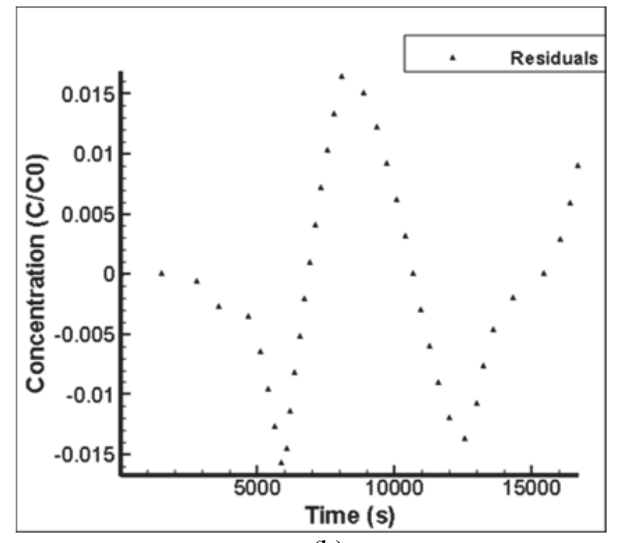

(b)

Fig. 10. Comparison of experimental and simulated concentrations of the outflow flux (a) and the residuals (b).

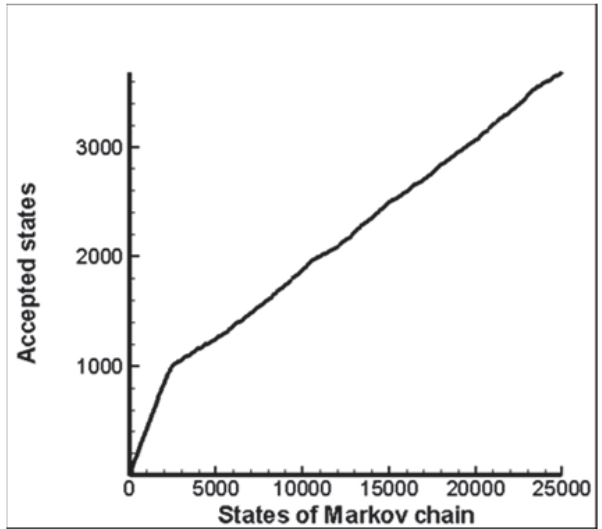

(a)

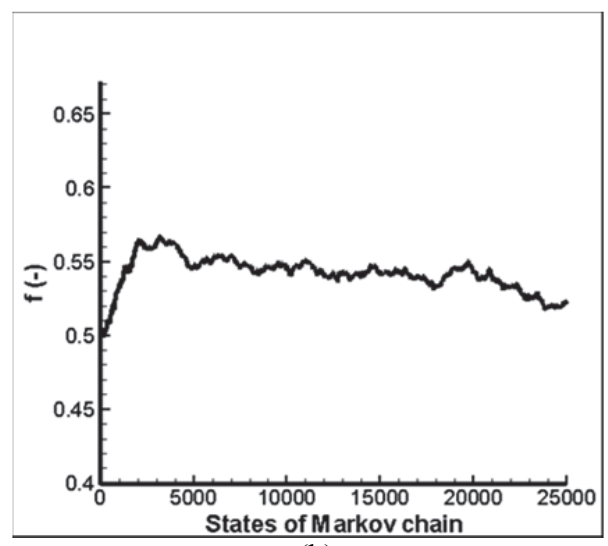

(b)

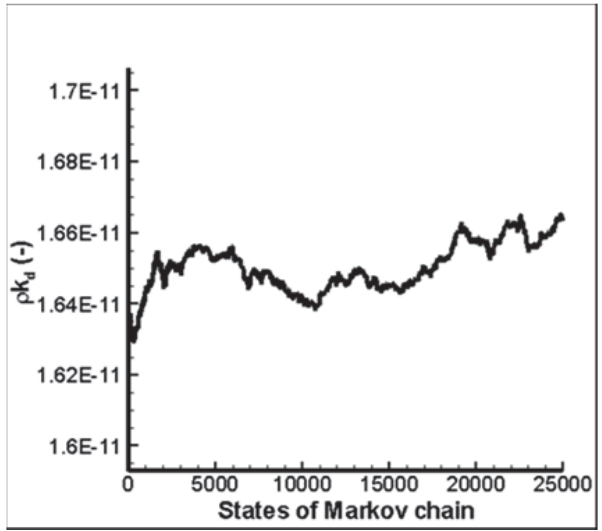

(c)

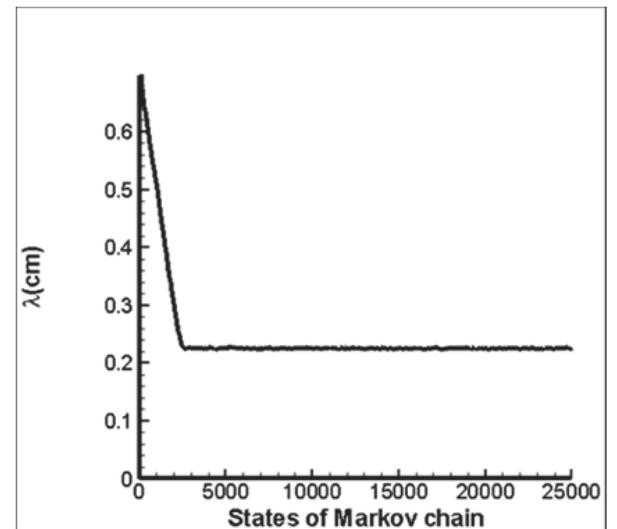

(d)

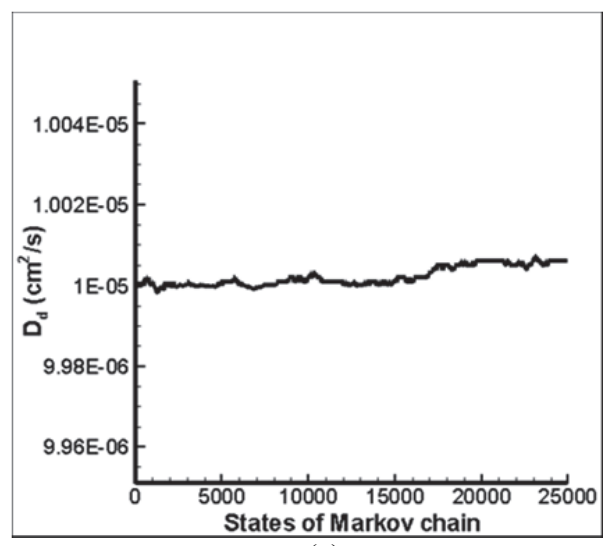

(e)

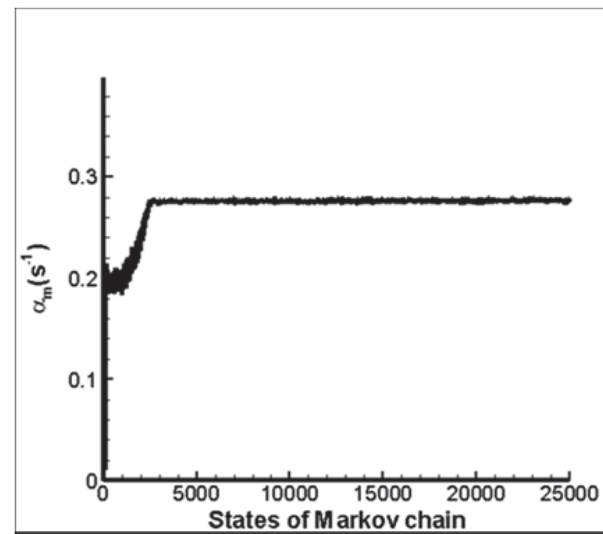

(f)

Fig. 11. States of the Markov chain for the solute transport parameters: (a) accepted states, (b) $f$, (c) $\rho_{b} K_{d}$, (d) $\lambda$, (e) $D_{d}$, and (f) $\alpha_{m}$. 
The evolution of accepted states and the Markov chains for the transport parameters are presented in Figure 11. A total of 25,000 states were considered for the Markov chains, with the last 10,000 states used to obtain the mean values and standard deviations of the marginal posterior distributions. The convergence of the chains was verified by using the method proposed by Geweke (1992), with the acceptance ratio corresponding to about $15 \%$ of the states of the Markov chain. Computational times for estimation of the hydraulic and transport parameters were of the order of 5 hours each, on a computer with an I5 $2.27 \mathrm{GHz}$ processor and 4.0 GByte of RAM memory.

Table 8. Prior distributions of the transport parameters used in the second step.

\begin{tabular}{l|c|c}
\hline Parameter & Distribution & Distribution information \\
\hline$f$ & Uniform & $\underline{\text { Interval: }(0,1)}$ \\
\hline$\rho_{b} K_{d}$ & Uniform & $\frac{\text { Interval: }\left(0.8 \overline{\rho_{b} K_{d}}, 1.2 \overline{\rho_{b} K_{d}}\right)}{\overline{\rho_{b} K_{d}}=1.637 \times 10^{-11}}$ \\
\hline$\lambda(\mathrm{cm})$ & Uniform & $\underline{\text { Interval: }(0.2 \bar{\lambda}, 1.8 \bar{\lambda})}$ \\
\hline$D_{d}\left(\mathrm{~cm}^{2} / \mathrm{s}\right)$ & Gaussian & $\underline{\text { Mean: }} \bar{D}_{d}=1.00 \times 10^{-1}$ \\
& & $\underline{\text { Standard Deviation: } 0.01 \bar{D}_{d}^{-5}}$ \\
\hline$\alpha_{m}\left(\mathrm{~s}^{-1}\right)$ & Uniform & $\underline{\text { Interval: }\left(0.01 \bar{\alpha}_{m}, 1\right)}$ \\
& & $\bar{\alpha}_{m}=1.00 \times 10^{-2}$ \\
\hline
\end{tabular}

Table 9. Estimated values of the transport parameters.

\begin{tabular}{l|c|c}
\hline Parameter & Mean & $99 \%$ Confidence Interval \\
\hline$f$ & 0.535 & $(0.514,0.557)$ \\
\hline$\rho_{b} K_{d}$ & $1.655 \times 10^{-11}$ & $(1.639,1.671) \times 10^{-11}$ \\
\hline$\lambda(\mathrm{cm})$ & 0.224 & $(0.222,0.226)$ \\
\hline$D_{d}\left(\mathrm{~cm}^{2} / \mathrm{s}\right)$ & $1.001 \times 10^{-5}$ & $\left(9.998 \times 10^{-6}, 1.003 \times 10^{-5}\right)$ \\
\hline$\alpha_{m}\left(\mathrm{~s}^{-1}\right)$ & 0.276 & $(0.273,0.279)$ \\
\hline
\end{tabular}

Due to correlation of the residuals observed in Figures 8 and 10 , a final analysis was performed in order to investigate the possibility of the measurements themselves being correlated. The parameters were again estimated by successively using only half of the measurements, that is, by halving the frequency of the original measurements. However, the estimated parameters and the residuals obtained with $50 \%$ and $25 \%$ of the original measurements were practically the same as those observed when $100 \%$ of the measurements were used. Therefore, the correlated residuals can be attributed to the strong linear dependency of the physical parameters shown in Figures 5-7, as well as to some mismatch between the adopted mathematical model and the physical processes of the problem. On the other hand, the small residuals observed for the measured concentration validate the use of the dual-porosity physical non-equilibrium model, in particular the hypotheses of having a constant $f$ (see Equations 12a,b) and a non-reactive tracer (KBr) (see Equation 13d) for our experiment.

\section{CONCLUSIONS}

In this study we used a Bayesian approach for solving a parameter estimation problem involving the simultaneous characterization of soil hydraulic and solute transport parameters by means of a small-scale laboratory soil column experiment. The Metropolis-Hastings algorithm of the Markov Chain Monte Carlo method was implemented for estimation of the unknown parameters. The sensitivity coefficients with respect to the model parameters were analyzed, revealing that pressure head (at the middle of the column) and outflow solute concentration measurements provided meaningful information for estimation of some of the unknowns. Even for such measurements, the sensitivity coefficients were generally very small, thus making the estimation procedure difficult and sensitive to measurement errors. For those parameters with small or linearly dependent sensitivity coefficients, Gaussian priors were utilized, based on direct measurements with other techniques. For the other parameters, non-informative uniform distributions were used as priors.

The estimation approach proposed in this work consisted of two steps. In the first step, the hydraulic parameters were estimated by using the measured data of the pressure head in the middle of the column. In the second step, these estimates of the flow parameters served as prior information for the coupled flowtransport problem, in which the transport parameters were estimated from the measured concentration data of the column discharge and of the pressure head in the middle of the column. Since the flow parameters were treated as random variables in the second step, they were also allowed to vary in the Markov chain in accordance with their prior distributions. The convergence of the Markov chain was verified by calculating the difference between the means in different ranges of the chain. Results revealed the accuracy and robustness of the estimation approach by producing small, although correlated, residuals.

Acknowledgements. The authors would like to thank Capes and $\mathrm{CNPq}$ for supporting this research.

\section{REFERENCES}

Abbaspour, K., Schulin, R., van Genuchten, M.Th., 2001. Estimating unsaturated soil hydraulic parameters using ant colony optimization. Adv Water Resour., 24, 827-841.

Abbaspour, K., Johnson, C., van Genuchten, M.Th., 2004. Estimating uncertain flow and transport parameters using a sequential uncertainty fitting procedure. Vadose Zone J., 3, $1340-1352$.

Beck, J., Arnold, K., 1997. Parameter Estimation in Engineering and Science. Wiley Interscience, New York.

Carducci, C.E., de Oliviera, G.C., da Costa, S., Zeviani, W.M., 2011. Modeling the water retention curve in Oxisols using the double van Genuchten equation. R. Bras. Ci. Solo., 35, 77-86. (In Portuguese.)

Dane, J.H., Topp, G.C., 2002. Methods of Soil Analysis, part 4, Physical Methods. Soil Sci. Soc. Am., Madison, WI.

De Smedt, F., Wierenga, P.J., 1984. Solute transfer through columns of glass beads. Water Resour. Res., 20, 225-232.

Diamantopoulos, E., Iden, S.C., Durner, W., 2012. Inverse modeling of dynamic nonequilibrium in water flow with an effective approach. Water Resour. Res., 48, W03503, doi: 10.1029/2011WR010717.

Franssen, H.J.H., Gómez-Hernández, J.J., Sahuquillo, A., 2003a. Coupled inverse modeling of groundwater flow and mass transport and the worth of concentration data. J. Hydrol., 281, 281-295.

Franssen, H.J.H., Stauffer, F., Kinzelbach, W., 2003b. Joint estimation of transmissivity and recharges-application: 
Stochastic characterization of well capture zones. J. Hydrol., 294, 1-3, 87-102.

Fu, J., Gómez-Hernández, J.J., 2009. Uncertainty assessment and data worth in groundwater flow and mass transport modeling using a blocking Markov chain Monte Carlo method. J. Hydrol., 364, 3-4, 328-341.

Geweke, J., 1992. Evaluating the accuracy of sampling-based approaches to the calculation of posterior moments. In: Bernardo, J., Berger, J., Dawid, A., Smith, A. (Eds): Bayesian Statistics. Oxford University Press, London.

Goldberg, S., Kabengi, N.J., 2010. Bromide adsorption by reference minerals and soils. Vadose Zone J., 9, 780-786.

Hastings, W. K., 1970. Monte Carlo Sampling Methods Using Markov Chains and Their Applications, Biometrika, 57, 97-109.

Hosseini, A.H., Deutsch, C.V., Mendoza, C.A., Biggar, K.W., 2011. Inverse modeling for characterization of uncertainty in transport parameters under uncertainty of source geometry in heterogeneous aquifers. J Hydrol., 405, 3-4, 402-416.

Kaipio, J., Somersalo, E., 2004. Statistical and Computational Inverse Problems. Applied Mathematical Sciences 160, Springer-Verlag.

Kaipio, J., Somersalo, E., 2007. Statistical inverse problems: discretization, model reduction and inverse crimes. J. Comp. Appl. Math, 198, 493-504.

Kohne, J., Mohanty, B., Simunek, J., 2006. Inverse dualpermeability modeling of preferential water flow in a soil column and implications for field-scale solute transport. Vadose Zone J., 5, 59-76.

Kool, J.B., Parker J.C., van Genuchten, M.T., 1985. Determining soil hydraulic properties from one-step outflow experiments by parameter estimation, I. Theory and numerical studies. Soil Sci. Soc. Am. J., 49, 1348-1354.

Laloy, E., Weynants, M., Bielders, C.L., Vanclooster, M., Javaux, M., 2010. How efficient are one-dimensional models to reproduce the hydrodynamic behavior of structured soils subjected to multi-step outflow experiments. J. Hydrol., 393, 1-2, 37-52, doi: 10.1016/ j.jhydrol.2010.02.017.

Lee, P., 2004. Bayesian Statistics. Oxford University Press, London.

Leij, F.J., Russell, W.B., Lesch, S.M., 1997. Closed-form expressions for water retention and conductivity data. Groundwater, 35, 5, 848-858.

Li, L., Zhou, H., Gómez-Hernández, J.J., Franssen, H.J.H., 2012. Jointly mapping hydraulic conductivity and porosity by assimilating concentration data via ensemble Kalman filter. J. Hydrol., 428-429, 152-169.

Maraqa, M.A., Wallace, R.B., Voice, T.C., 1997. Effect of degree of saturation on dispersivity and immobile water in sandy columns. J. Contam. Hydrol., 25, 199-218.

Melamed, R., Jurinak, J.J., Dudley, L.M., 1994. Anion exclusion - pore water velocity interaction affecting transport of bromine through an Oxisol. Soil Sci. Soc. Am. J., 58, 14051410 .

Metropolis, N., Rosenbluth, A., Rosenbluth, M., Teller, A., Teller, E., 1953. Equation of state calculation by fast computing machines. J. Chemical Phys., 21, 1087-1092.

Miller, C.T., Dawson, C.N., Farthing, M.W., Hou, T.Y., Huang, J., Kees, C.E., Kelley, C.T., Langtangen, H.P., 2013. Numerical simulation of water resources problems: Models, methods, and trends. Adv. Water Resour., 51, 405-437.

Nkedi-Kizza, P., Biggar, J.W., Selim, H.M., van Genuchten, M.Th., Wierenga, P.J., Davidson, J.M., Nielsen, D.R., 1984. On the equivalence of two conceptual models for describing ion exchange during transport through an aggregated oxisol. Water Resour. Res., 20, 8, 1123-1130.
Orlande, H.R.B., van Genuchten, M.Th., Cotta, R.M., Moreira, P.H., 2009. Bayesian estimation of hydraulic and solute transport parameters from laboratory soil column experiments. In: Proc. Int. Symp. Convective heat and mass transfer in sustainable energy, Hammamet, Tunisia, 20 p.

Özisik, M.N., Orlande, H.R.B., 2000. Inverse Heat Transfer: Fundamentals and Applications. Taylor and Francis, New York.

Parker, J.C., Kool, J.B., van Genuchten, M.Th., 1985. Determining soil hydraulic properties from one-step outflow experiments by parameter estimation. II. Experimental studies. Soil Sci Soc. Am. J., 49, 1354-1359.

Raithby, G.D., Torrance, K.E., 1974. Upstream-weighted differencing scheme and their application to elliptic problems involving fluid flow. Computers \& Fluids, 2, 191-206.

Schaap, M.G., Leij, F.J., van Genuchten, M.Th., 2001. Rosetta: A computer program for estimating hydraulic parameters with hierarchical pedotransfer functions. J Hydrol., 251, 163-176.

Si, B.C., Kachanoski, R.G., 2000. Estimating soil hydraulic properties during constant flux infiltration: Inverse procedures. Soil Sci. Soc. Am. J., 64, 2, 439-449.

Šimůnek, J., Jarvis, N., van Genuchten, M.Th., Gardenas, A., 2003. Review and comparison of models for describing nonequilibrium and preferential flow and transport in the vadose zone. J. Hydrol., 272, 14-35.

Šimůnek J., Bradford S.A., 2008. Vadose zone modeling: Introduction and importance. Vadose Zone J., 7, 2, 581-586.

Šimůnek, J., Šejna, M., Saito, H., Sakai, M., van Genuchten, M. Th., 2013. The HYDRUS-1D Software Package for Simulating the Movement of Water, Heat, and Multiple Solutes in Variably Saturated Media, Version 4.16, HYDRUS Software Series 3, Department of Environmental Sciences, University of California Riverside, Riverside, California, USA, 340 p. (http://www.pc-

progress.com/Downloads/Pgm_hydrus1D/HYDRUS1D4.16.pdf).

Shackelford, C.D., 1991. Laboratory diffusion testing for waste disposal - A review. J. Contam. Hydrol., 7, 177-217.

Sommer, R., Fölster, H., Vielhauer, K., Maklouf, E.J., Vlek, P.J.G., 2003. Deep soil water dynamics and depletion by secondary vegetation in the Eastern Amazon. Soil Sci. Soc. Am. J., 67, 1672-1686.

Spohrer, K., Herrmann, L., Ingwersen, J., Stahr, K., 2006. Applicability of uni- and bimodal retention functions for water flow modeling in a tropical Acrisol. Vadose Zone J., 5, $48-58$.

Tan, S., Fox, C., Nicholls, G., 2006. Inverse Problems. Course Notes for Physics 707. University of Auckland, Auckland.

van Genuchten, M.Th., Wierenga, P.J., 1976. Mass transfer studies in sorbing porous media, I. Analytical solutions. Soil Sci. Soc. Am. J., 40, 4, 473-480.

van Genuchten, M.Th., 1978. Calculating the unsaturated hydraulic conductivity with a new closed-form analytical model. Hydrology Document Number 412. Department of Civil Engeneering, Princeton University, Princeton, New Jersey, USA.

van Genuchten, M.Th., 1980. A closed form equation for predicting the hydraulic conductivity of unsaturated soils. Soil Sci. Soc. Am. J., 44, 5, 892-898.

van Genuchten, M.Th., Nielsen, D.R., 1985. On describing and predicting the hydraulic properties of unsaturated soils. Annales Geophysicae, 3, 5, 615-628.

Vrugt, J.A., Gupta, H.V., Dekker, S.C., Sorooshian, S., Wagener, T., Bouten, W., 2006. Application of stochastic 
parameter optimization to the Sacramento soil moisture accounting model. J. Hydrol., 325, 288-307.

Vrugt, J.A., ter Braak, C.J.F., Diks, C.D.H., Schoups, G., 2013. Hydraulic data assimilation using particle Markov chain Monte Carlo simulation: Theory, concepts and applications. Adv. Water Res., 51, 457-478.

Xu, T., Gómez-Hernández, J.J., Zhou, H., Li, L., 2013. The power of transient piezometric head data in inverse modeling: An application of the localized normal-score EnKF with covariance inflation in a heterogenous bimodal hydraulic conductivity field. Adv. Water Res., 53, 100-118.
Yates, S.R., van Genuchten, M.Th., Warrick, A.W., Leij, F.J., 1992. Analysis of measured, predicted, and estimated hydraulic conductivity using the RETC computer program. Soil Sci. Soc. Am. J., 56, 2, 347-354.

Zhou, H., Gómez-Hernández, J.J., Franssen, H.J.H., Li, L., 2011. An approach to handling non-Gaussianity of parameters and state variables in ensemble Kalman filtering. Adv. Water Res., 34, 7, 844-864.

Received 4 November 2014 Accepted 15 September 2015 